\title{
AN ECONOMIC STUDY FOR THE USE OF AGRICULTURAL MECHANIZATION IN THE PRODUCTION OF WHEAT CROP IN NEWLY RECLAIMED LAND (Case Study: West EL Menia Area)
}

(Received: 19.3.2018)

\author{
By \\ M. A. A. Abo El Naga \\ Department of Economic Studies, Economic and Social Studies Division, \\ Desert Research Center, Cairo, Egypt
}

\begin{abstract}
The present study aimed to examine the effect of the use of technological patterns on the economics of wheat production in newly reclaimed lands in Minya Governorate, Egypt. The research relied mainly on preliminary data obtained through the questionnaire conducted by wheat farmers in the study area during the agricultural year 2016/2017. In addition the secondary data were obtained from the annual statistical publications issued by the Ministry of Agriculture and Land Reclamation, the Central Agency for Public Mobilization and Statistics, Egypt, in addition to some references, theses and scientific research related to the subject of the research. According to the productivity and economic efficiency indicators, the superiority of the third technological pattern (Alcombiaan) compaird to the counterparts, first the traditional, and second the self or attached Mowers, which led to a decrease in the variable costs of wheat crop around 800.75, 649.25 pounds per acre for the first technological style (traditional), and the second (self or attached mowers) respectively. Also led to increased productivity by about $1.25,0.75$ ardebs, the first technological style, and second, respectively. which reflected the increase in revenue per feddan for the third pattern by about 860.720 pounds per acre for technological style.

The superiority of the third technolgy pattern was also reflected in its first and second counterparts with respect to the results of the estimation of the income and cost criteria and the price and quantity of the tie to cover variable and total costs. The most important inputs affecting the quantity of wheat production used for the three technological types are seven resources (human labor quantity, number of irrigation hours, amount of nitrogen fertilizer, number of hours of study machines, number of hours of autoclave or attachment, number of hours of operation of tractors, The value of the production elasticity of these inputs is less than the correct one, which means that the producers of wheat produce the second stage of production (the economic phase).
\end{abstract}

Key words: newly reclaimed lands, wheat - agricultural mechanization, style, price of parity, amount of the tie, economic stage.

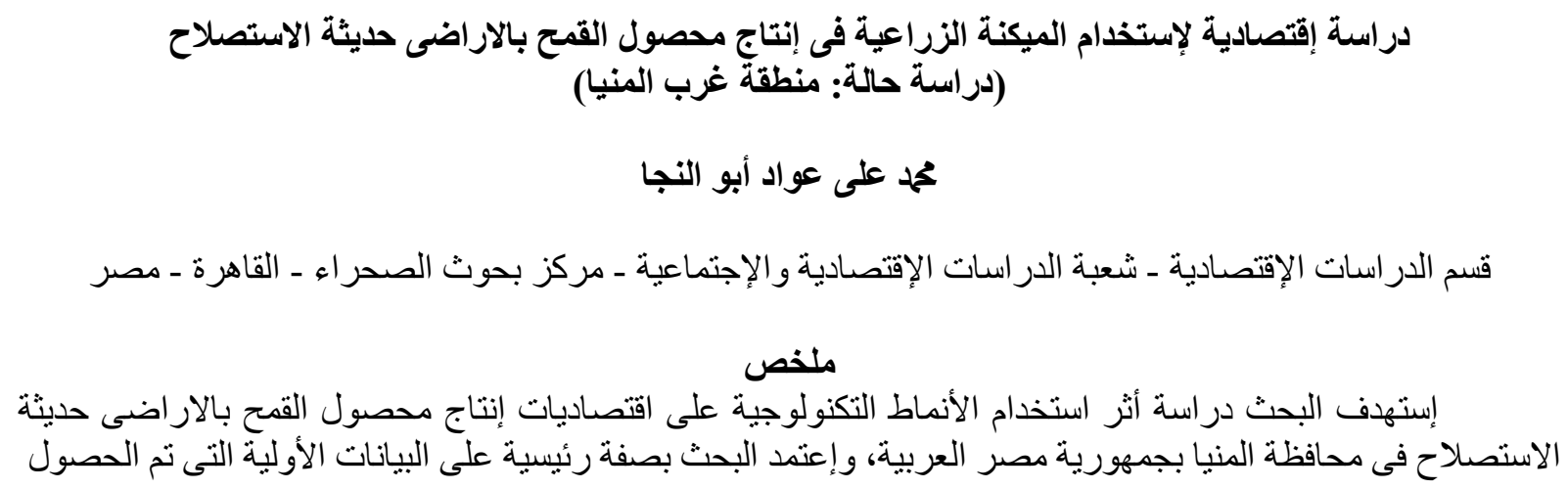




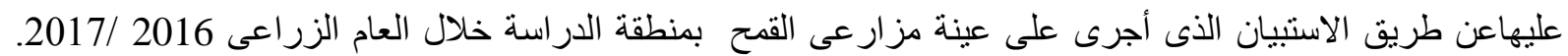

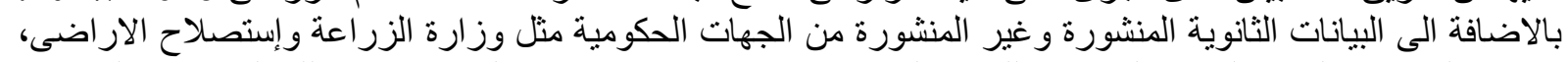

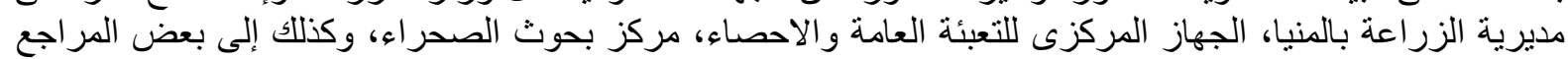

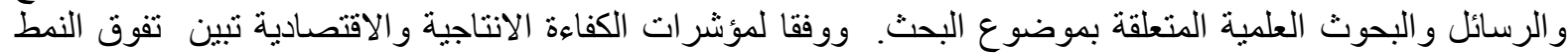

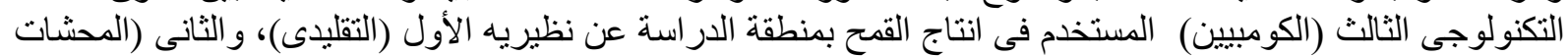

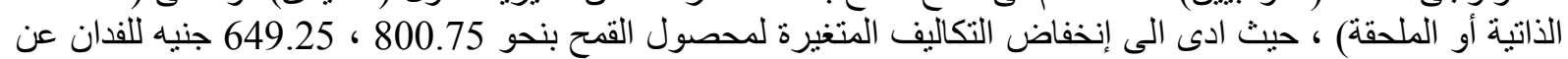

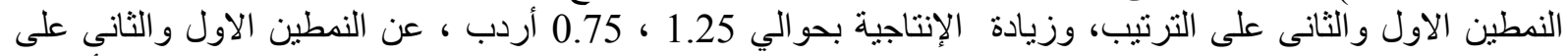

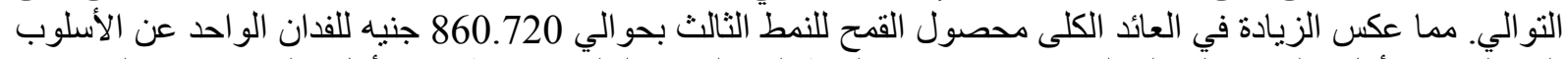

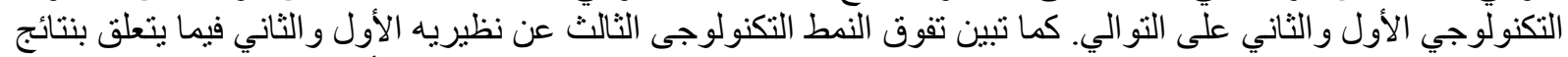

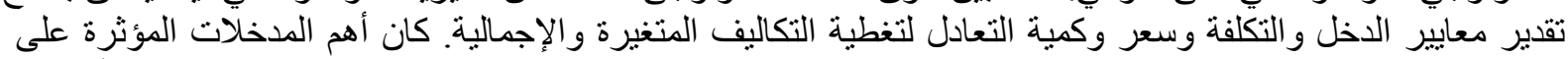

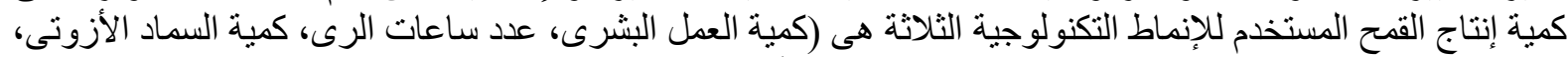

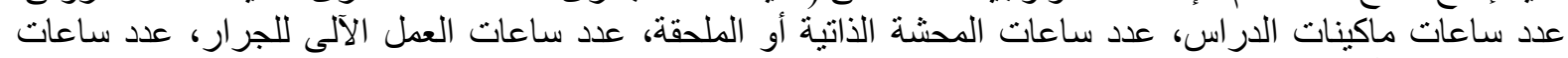

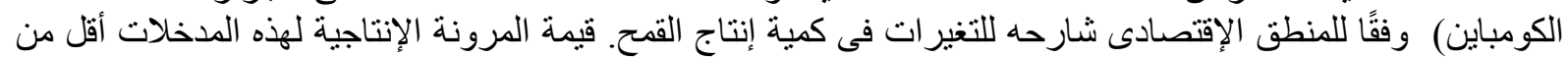

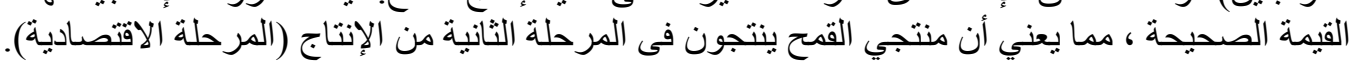

الاسعار العالمية ومن ثم زيادة دخل المزارعين وبالتالى زيادة المساحة المنزر عة بهـ فيه

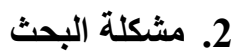

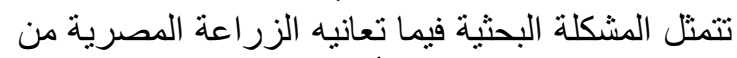

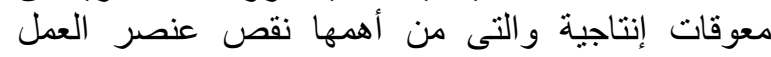

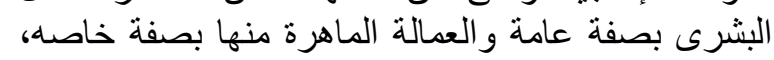

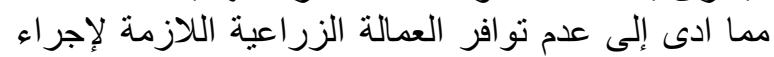

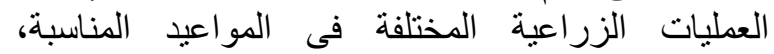

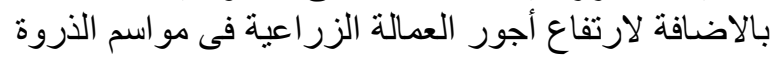

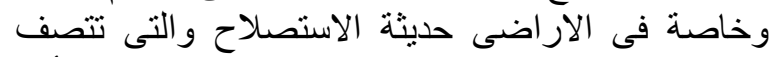

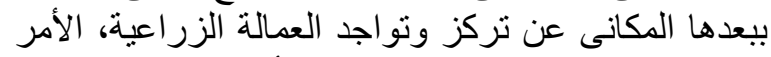

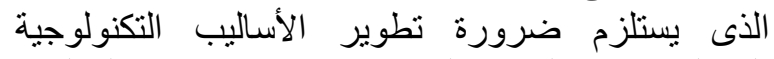

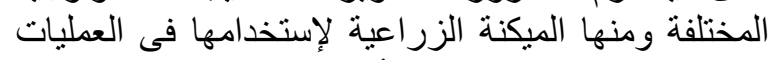

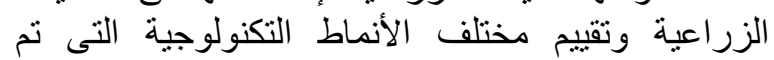

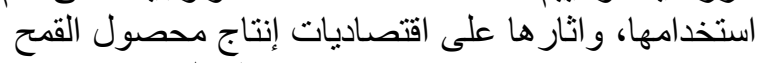
فى الار اضى حديثة الاستصلاح بمحافظة النئة المنيا.

\section{3.}

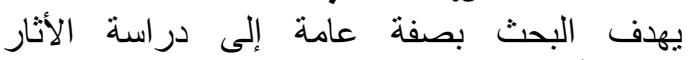

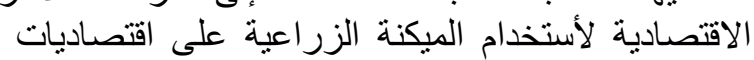

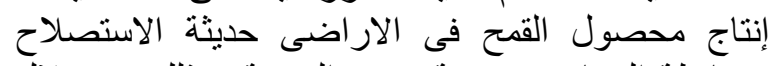
بمحافظة المنيا، جمهورية مصر العربية العربية، وذلك من خلال الإنل

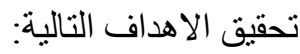

1.3. دراسة تطور المساحة المزروعة والإلتهاجة الإنتاجية الفدانية

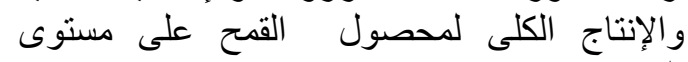
الجمهورية.

2.3. دراسة تطور الانتاج والاستهلاك المحلى والاكلى والفجوة

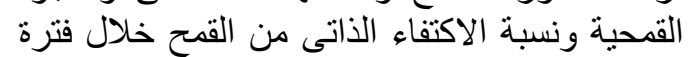
الدر اسة.

3.3. دراسة أثر أستخدام الميكنة الزراعية أو الخدمة الآلية

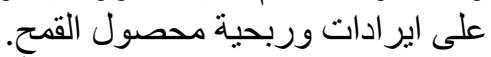

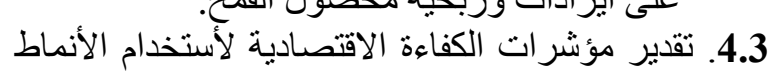
التكنولوجية المختلفة بعينة الدراسة.

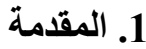

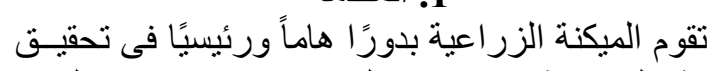

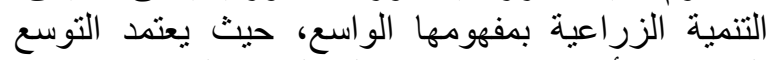

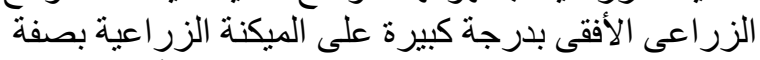

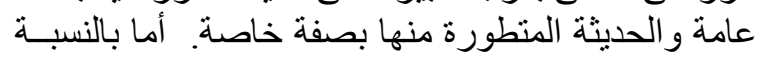

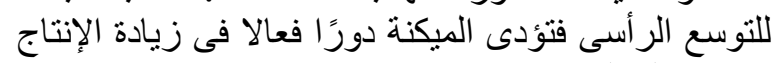

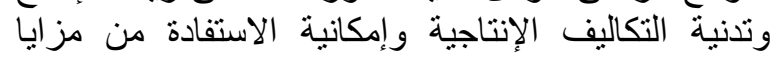

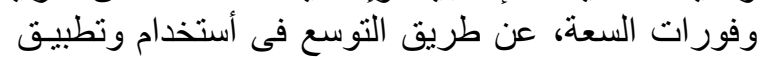

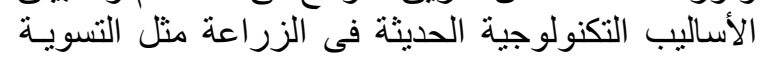

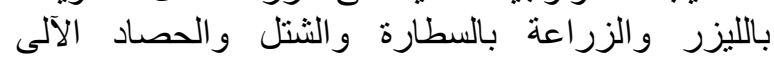

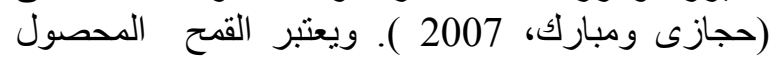

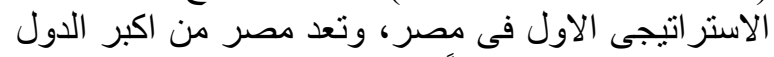

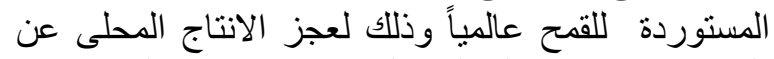

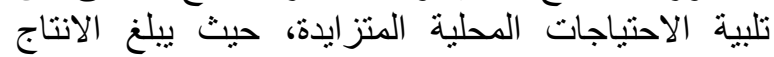

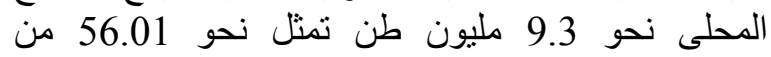

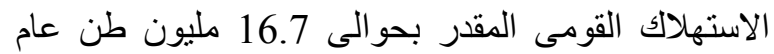

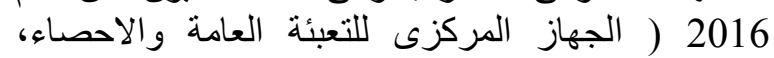
2017.). الامر الذى يحمل ميزانية الدولة العباء الدئة كبيرة

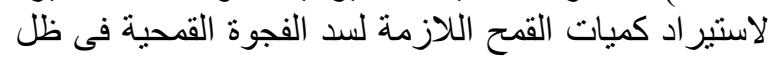

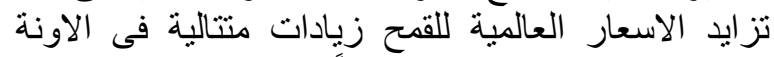

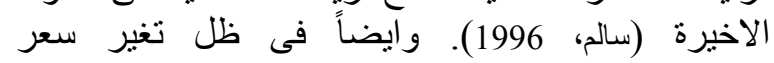

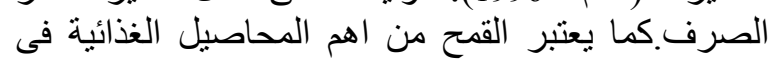

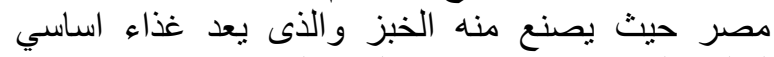

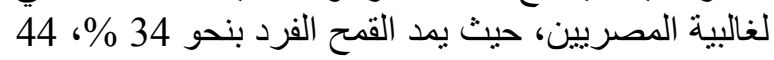

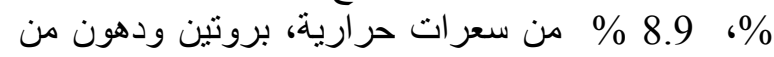
جملة ما يحصل عليه الفرد فى غذائه الئه اليومى (حسن،

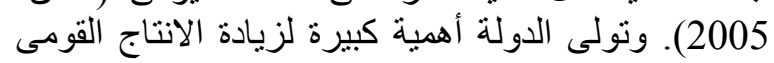

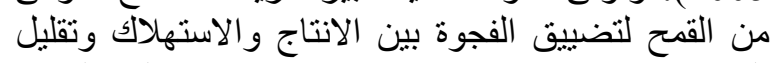

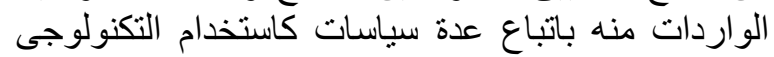

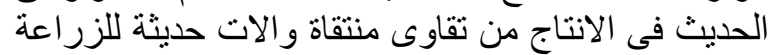

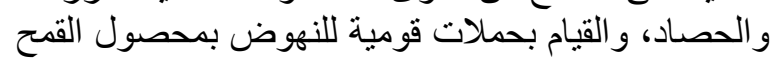

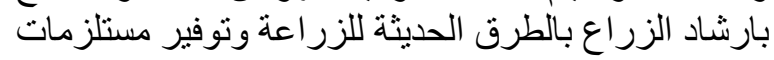

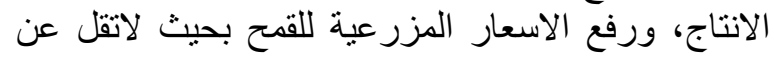




\section{6. عينة الار اسة}

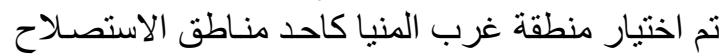

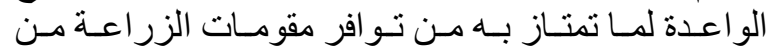

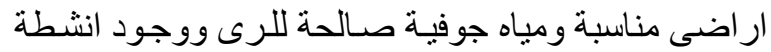

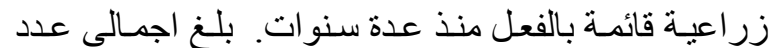
مزارع القمح بمنطقة غرب المنيا بمحافظة المنيا نحو 97

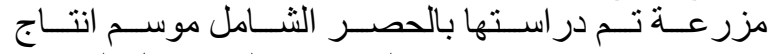

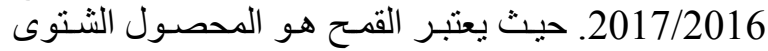

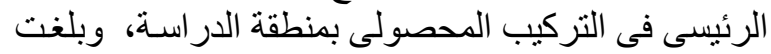

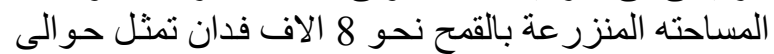

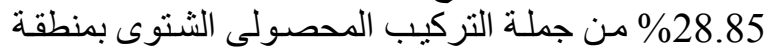

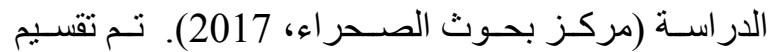

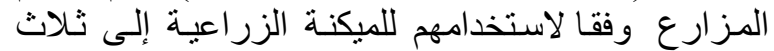

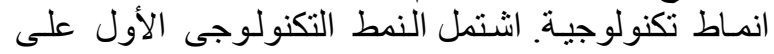

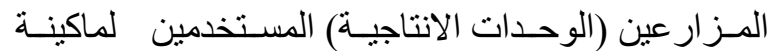

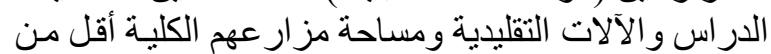

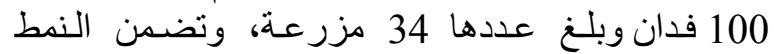
التكنولوجى الثانى على المز ارعين (الوحدات الانتاجيـة)

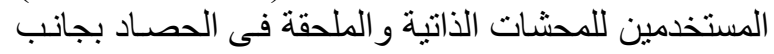

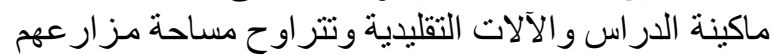

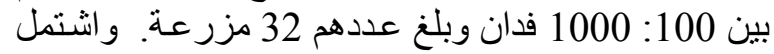

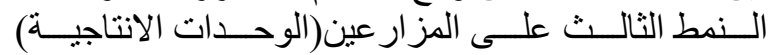

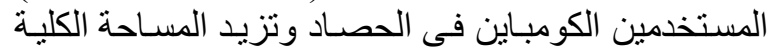
لمزار عهم عن الف فدان وبلغ عددهم 31 مز ارع.

\section{7. النتائج البحثية والمناقشة}

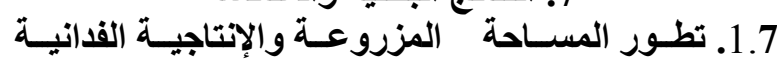

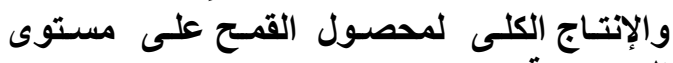
الجمهورية الإنية

1.1.7. تطور المساحة المزروعة: باستعر اض البيانات

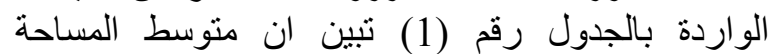

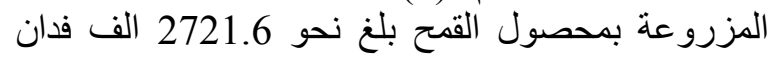

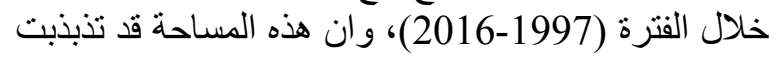

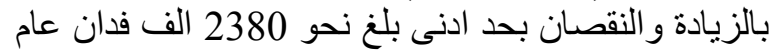

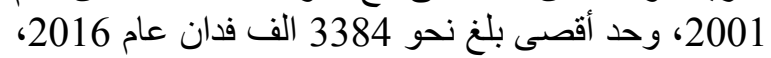

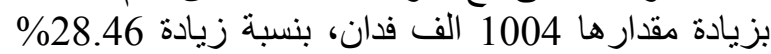

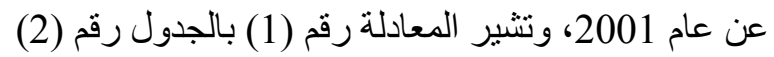

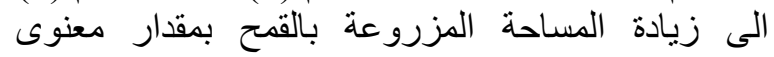

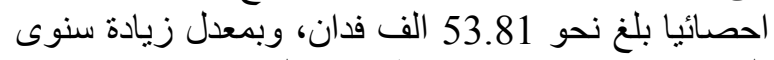

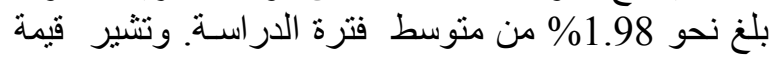

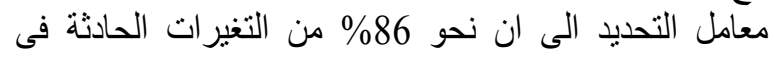
المساحة المزروعة بالقمح ترجع الى التهير التغيرات التى يعكسها

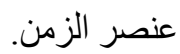

5.3. التحليل الاقتصادى والقياسى لدوال إنتاج القمح وفقًا

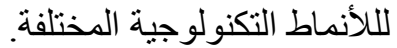

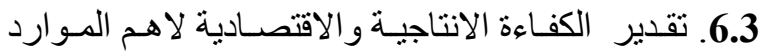
المستخدمة فى انتاج محصول القمح بعينة الدر اسة.

\section{4. الأسلوب البحثى ومصادر البيانات}

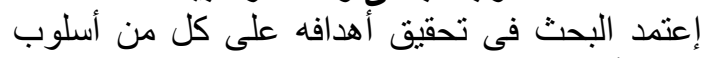

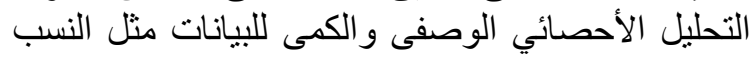

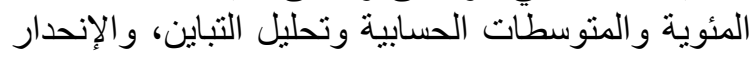
المتعدد، بالاضافة لاستخدام بعض مقاييس الإنية الكفاءة الانتاجية الإنية

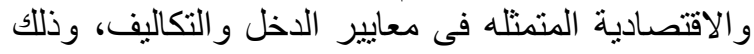
بهدف تفسير وتحليل العلاقات التهائ التى تحكم المتغيرات

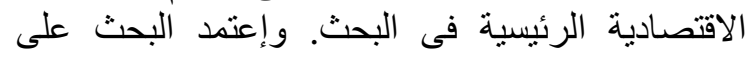

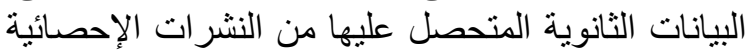

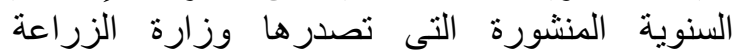

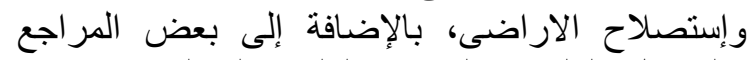

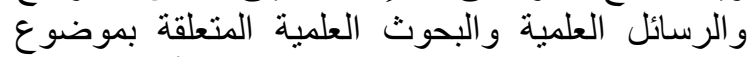

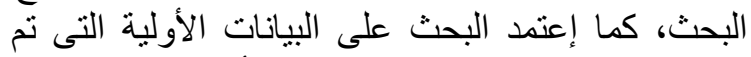

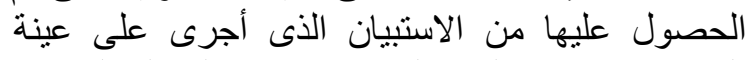

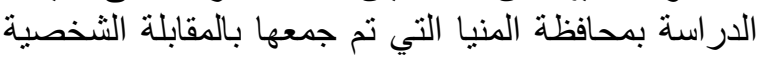

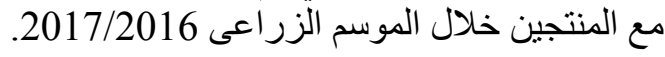

\section{5نط قة الدراسة}

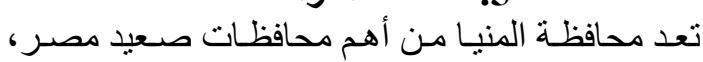

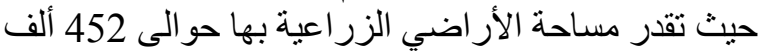

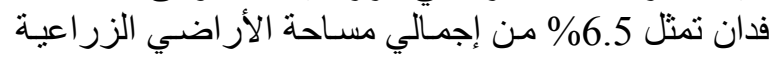

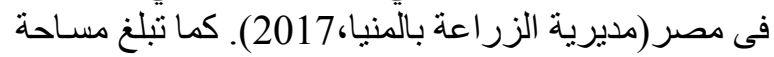

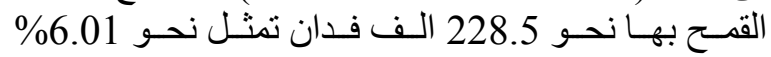

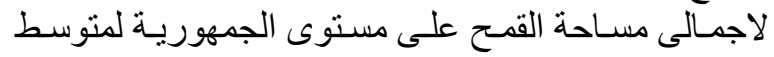

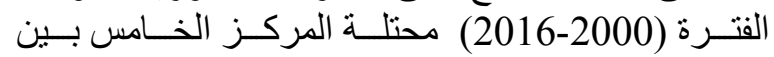

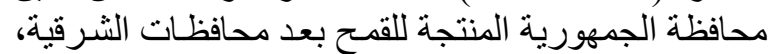
البحيرة، الدقهلية وكفر الثيخ ( الجهاز المركزى للتعبئة

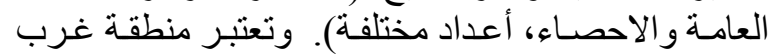

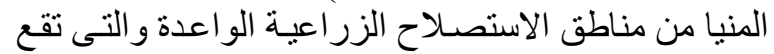

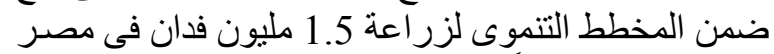

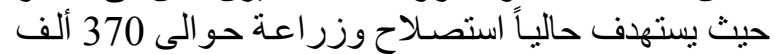
فدان تمثل 24.7 \% من المساحة الكلية المستهدف زر اعتى اعتها

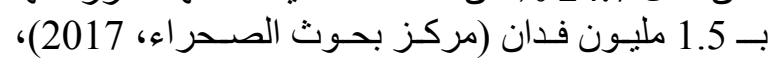

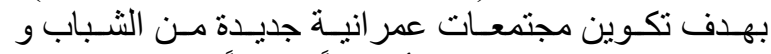

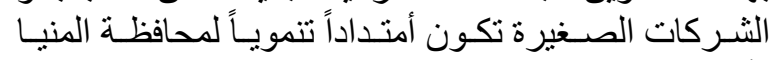

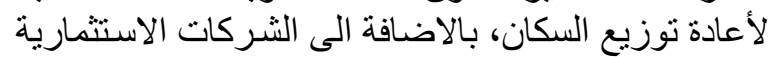

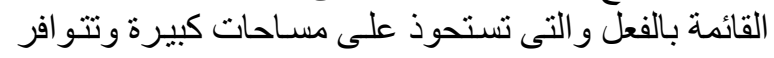
ل الديها كل الامكانات المادية. 


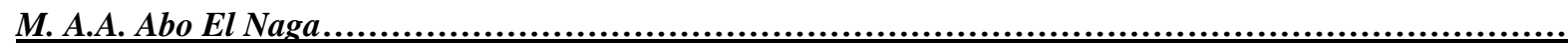

جدول رقم (1): تطور المساحة المزروعة والإنتاجية الفدانية والإنتاج الكلى لمحصول القـح علي مستوي الجمهورية خلال الفترة (1997-12016).

\begin{tabular}{|c|c|c|c|}
\hline الانتاج الكلى (الف طن) & الانتاجية ( طن/فدان) & المساحة (الف فدان) & السنوات \\
\hline 5747.88 & 2.28 & 2521 & 1997 \\
\hline 5761.98 & 2.38 & 2421 & 1998 \\
\hline 5844.45 & 2.35 & 2487 & 1999 \\
\hline 6100.92 & 2.52 & 2421 & 2000 \\
\hline 6354.6 & 2.67 & 2380 & 2001 \\
\hline 6576.21 & 2.67 & 2463 & 2002 \\
\hline 6253.14 & 2.67 & 2342 & 2003 \\
\hline 6223 & 2.54 & 2450 & 2004 \\
\hline 6923.28 & 2.73 & 2536 & 2005 \\
\hline 7166.5 & 2.75 & 2606 & 2006 \\
\hline 8149.05 & 2.73 & 2985 & 2007 \\
\hline 8272.8 & 2.7 & 3064 & 2008 \\
\hline 7414.68 & 2.73 & 2716 & 2009 \\
\hline 7971.6 & 2.73 & 2920 & 2010 \\
\hline 8528.37 & 2.71 & 3147 & 2011 \\
\hline 7142.38 & 2.38 & 3001 & 2012 \\
\hline 5634.75 & 2.75 & 2049 & 2013 \\
\hline 8787.58 & 2.78 & 3161 & 2014 \\
\hline 8816.58 & 2.61 & 3378 & 2015 \\
\hline 9272.16 & 2.74 & 3384 & 2016 \\
\hline 7147.096 & 2.621 & 2721.6 & المتوسط \\
\hline
\end{tabular}

المصدر: جمعت وحسبت من وزارة الزراعة واستصلاح الاراضى، قطاع الشئون الاقتصادية، نشرة الإقتصاد الزراعى.

ادنى بلـغ نحو 16747.88 الف طن عـام 1997، وحد أقصىى

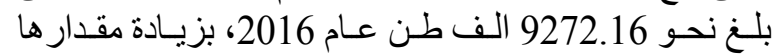

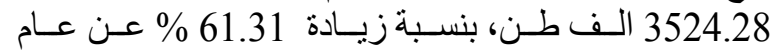

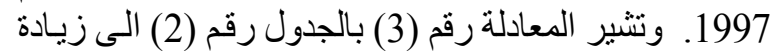

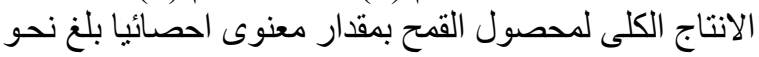

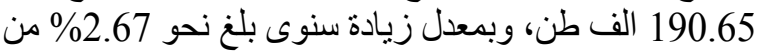
متوسط فترة الدر اسة. وتنير قيمة معامل التحديد الى الى ان نحو

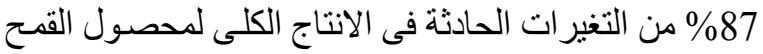

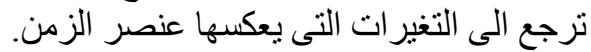

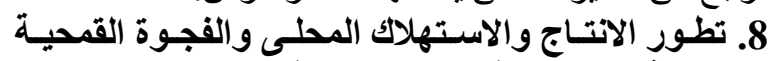

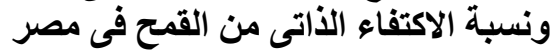
1.8 الاستهلاك المحلى من القمح من الأح فئح

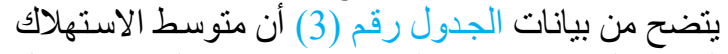

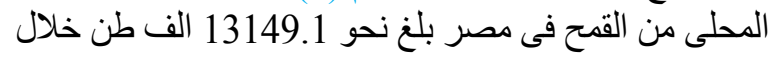

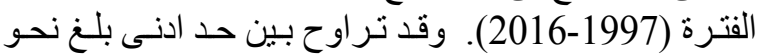
10450 الف طن عام 2001، وحد اقصسى بلـغ نحو 18182

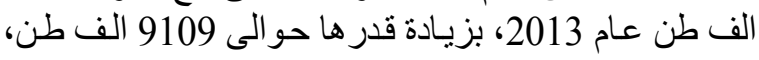

2.1.7. تطور الانتاجية الفدانية: باستعر اض البيانات الواردة بالجدول رقم (1) تبين ان متوسط الانتاجية الفدانية لمحصول

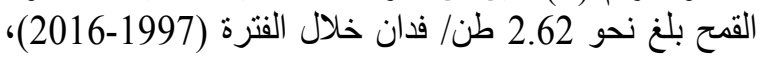

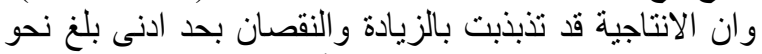

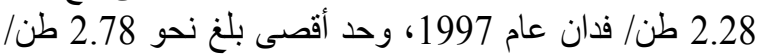

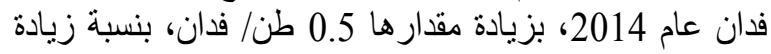

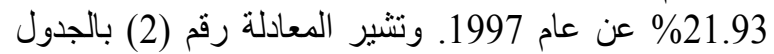
رقم (2) الى زيادة الانتاجية الفدانية لمحصول القمح بمقدار

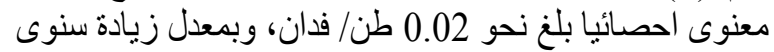

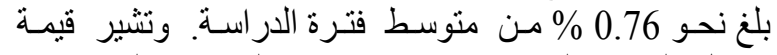

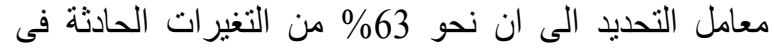
الانتاجية الفدانية لمحصول القمح ترجع الى التى التغيرات التى التى التى التى

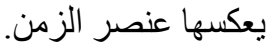
3.1.7. تطور الانتـاج الكلى: باستعر اض البيانـات الواردة

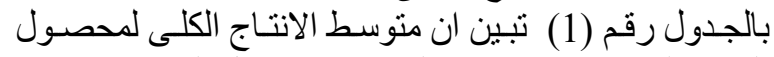

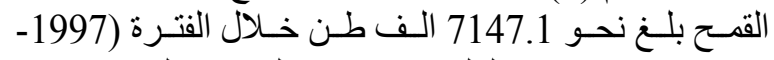

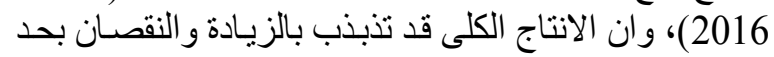


بلـغ نحو 2819.86 الف طن عـام 2003، وحد اقصسى بلـغ نحو

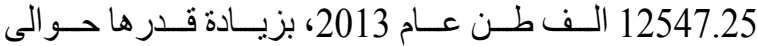

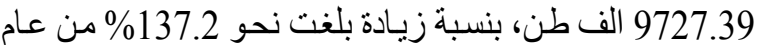

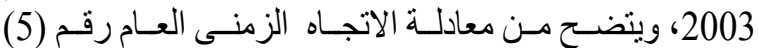

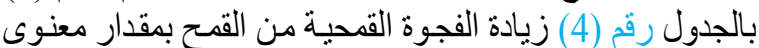

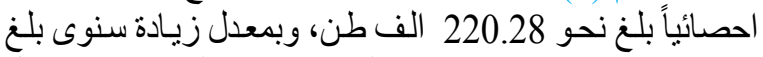
نحو 5.64\% مـن متوسط فترة الدر اسـة، كمـا بلغت قيمـة معامـل
بنسبة زيادة بلغت نحو 73.99\% عن عام 2001. ويتضح من الز

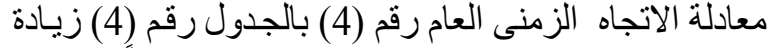
الاستهلاك المحلى من القمح بمقدار معنوى احصـائياً بلـغ نحو

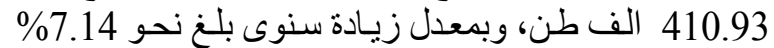

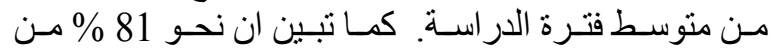

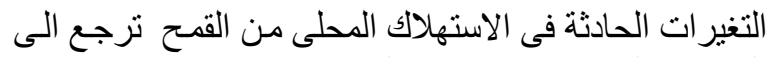

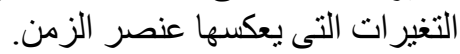

جدول رقم (2): معادلات الإتجاه الزمني العام لتطور مساحة وإنتاجية وإنتاج محصول القمح في مصر خلال الفترة (1997-2016).

\begin{tabular}{|c|c|c|c|c|c|c|c|c|}
\hline \multirow{2}{*}{ معدل التغير (\%) } & \multirow{2}{*}{ المتوسط } & \multirow{2}{*}{$F$} & \multirow{2}{*}{$\mathbf{R}$} & \multicolumn{2}{|c|}{ معامل الإنحدار } & \multirow{2}{*}{ المقدار الثابت } & \multirow{2}{*}{ المعادلة } & \multirow{2}{*}{ البيان } \\
\hline & & & & $(\mathbf{t})$ & $B$ & & & \\
\hline 1.98 & 2721.60 & ${ }^{* *} 84.37$ & 0.86 & "31.46 & 53.81 & 2255.418 & 1 & المسـاحة \\
\hline 0.76 & 2.62 & "* 14.24 & 0.63 & $" 4.31$ & 0.02 & 2.438 & 2 & الإنتاجية \\
\hline 2.67 & 7147.096 & "119.87 & 0.87 & $" 11.12$ & 190.65 & 5312 & 3 & الإنتاج \\
\hline
\end{tabular}

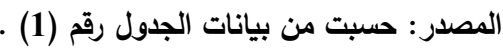

جدول رقم (3): تطور الانتاج والاستهلاك المحلى والفجوة القمحية ونسبة الاكتفاء الذاتى من القمح فى مصر على مستوى الجمهورية خلال الفترة (1997-1916).

\begin{tabular}{|c|c|c|c|c|}
\hline نسبة الاكتفاء الأتى & الفجوة القحية (الف طن) & الاستهلاك (الف طن) & الاتتاج الكلى (الف طن) & السنوات \\
\hline 53.25 & 5047.12 & 10795 & $\mathbf{5 7 4 7 . 8 8}$ & 1997 \\
\hline 53.89 & 4931.02 & 10693 & 5761.98 & 1998 \\
\hline 54.67 & 4845.55 & 10690 & 5844.45 & 1999 \\
\hline 52.94 & 5423.08 & 11524 & 6100.92 & 2000 \\
\hline 60.81 & 4095.4 & 10450 & 6354.6 & 2001 \\
\hline 60.52 & 4289.79 & 10866 & 6576.21 & 2002 \\
\hline 68.92 & 2819.86 & 9073 & 6253.14 & 2003 \\
\hline 55.78 & 4933 & 11156 & 6223 & 2004 \\
\hline 63.46 & 3986.72 & 10910 & 6923.28 & 2005 \\
\hline 62.07 & 4378.5 & 11545 & 7166.5 & 2006 \\
\hline 58.57 & 5764.95 & 13914 & 8149.05 & 2007 \\
\hline 58.70 & 5821.2 & 14094 & 8272.8 & 2008 \\
\hline 55.79 & 5875.32 & 13290 & 7414.68 & 2009 \\
\hline 51.91 & 7386.4 & 15358 & 7971.6 & 2010 \\
\hline 55.18 & 6927.63 & 15456 & $\mathbf{8 5 2 8 . 3 7}$ & 2011 \\
\hline 47.28 & 7964.62 & 15107 & 7142.38 & 2012 \\
\hline 30.99 & 12547.25 & 18182 & 5634.75 & 2013 \\
\hline 53.05 & 7776.42 & 16564 & 8787.58 & 2014 \\
\hline 52.86 & 7861.42 & 16678 & $\mathbf{8 8 1 6 . 5 8}$ & 2015 \\
\hline 55.73 & 7364.84 & 16637 & 9272.16 & 2016 \\
\hline 55.32 & 6002.00 & 13149.10 & 7147.10 & المتوسط \\
\hline
\end{tabular}

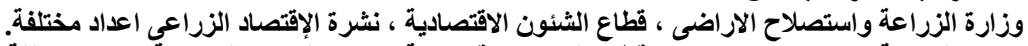

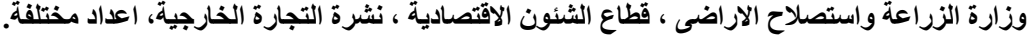

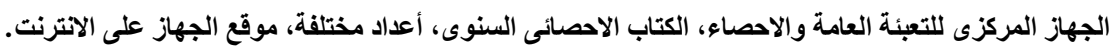

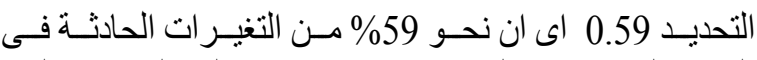

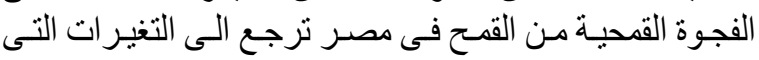
يعكسا عنصر الزمن.

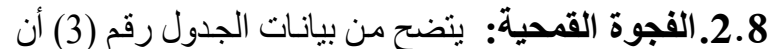

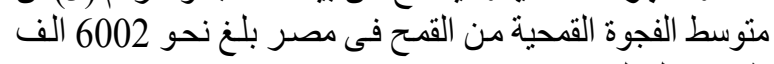

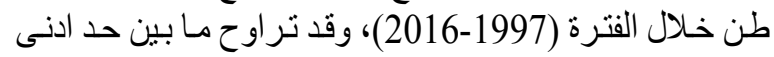




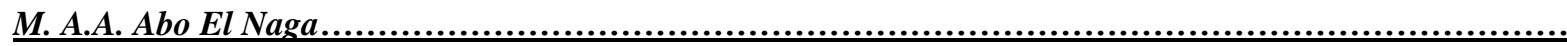

جدول رقم (4): معادلات الإتجاه الزمني العام لتطور الانتاج والاستهلاك المحلى والفجوة القحية ونسبة الاكتفاء الذاتى من القصح

فى مصر على مستوى الجمهورية خلال الفترة (1997-2016).

\begin{tabular}{|c|c|c|c|c|c|c|c|c|}
\hline \multirow{2}{*}{ معدل التغير } & \multirow{2}{*}{ المتوسط } & \multirow{2}{*}{$\mathbf{F}$} & \multirow{2}{*}{$\mathbf{R}$} & \multicolumn{2}{|c|}{ معامل الإنحدار } & \multirow{2}{*}{ المقدار الثابت } & \multirow{2}{*}{ رقم } & \multirow{2}{*}{ البيان } \\
\hline & & & & $(\mathbf{t})$ & $B$ & & & \\
\hline 7.14 & 13149.10 & $* * 78.71$ & 0.81 & $* * 8.864$ & 410.92 & 8841.564 & 4 & الاستهلاك الكلى \\
\hline 5.64 & 6002.0 & $* * 24.961$ & 0.59 & **5.014 & 220.28 & 3526.621 & 5 & الفجوة القححية \\
\hline 0.47 & 55.32 & 0.078 & 0.27 & $1.278^{-}$ & 0.261 & 56.094 & 6 & \% للاكتفاء الذاتى \\
\hline
\end{tabular}

(***) معنوية عذ 1 \% مستوى.

المصدر: حسبت من بيانات الجدول رقم (4).

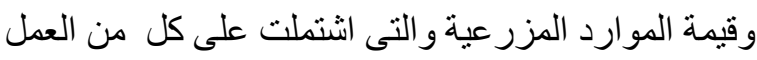

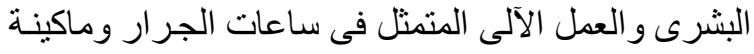

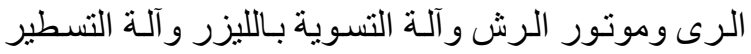

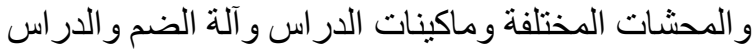

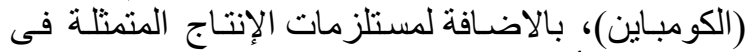

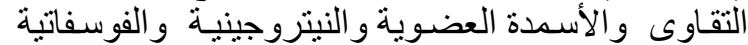
وكمية المبيدات المستخدمة للفدان من القهـ وكميـة النـاتج

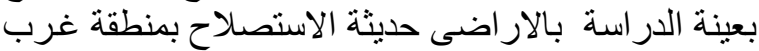

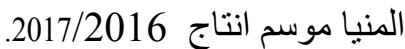
1.9. تكاليف العمل المزرعى لباج

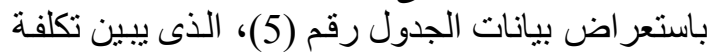

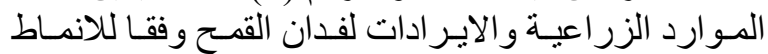

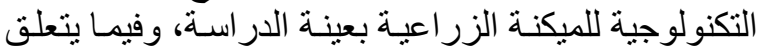

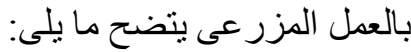

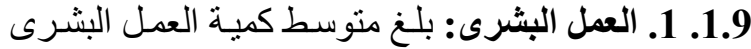
لفدان القمح بالمز ارع المستخدمة للنمط التكنولوجى الأول

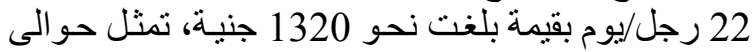

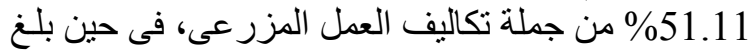
منوسط كمية العمل البشرى المستخدم فى كل من النئ النمطين فين

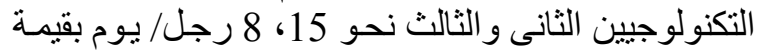

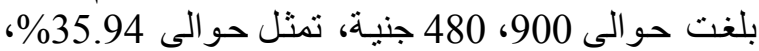

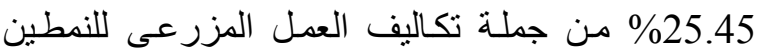

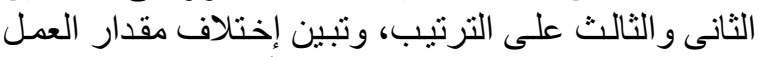

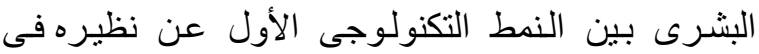

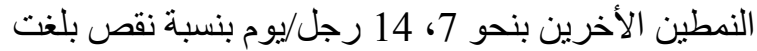

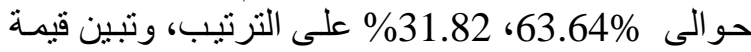

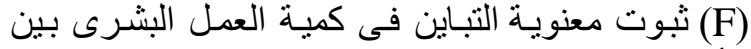

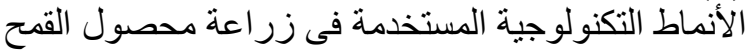

بالعينة.

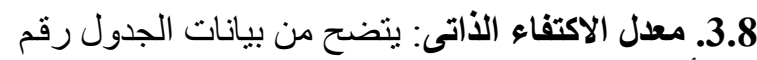

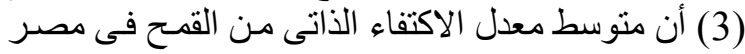

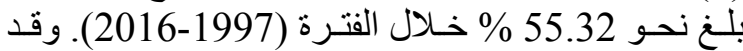
تر اوح بين حد ادنى بلغ نحو 32 \% 30.99 \% عام 203 \% 2013 وحد ولد

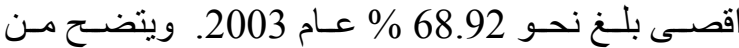

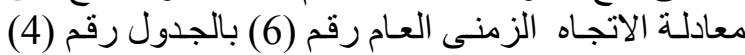

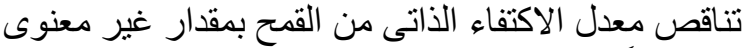

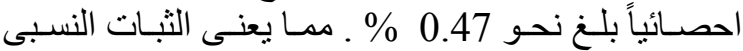

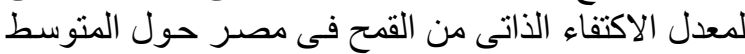

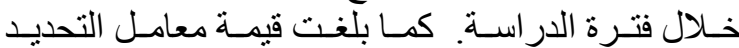

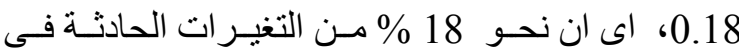

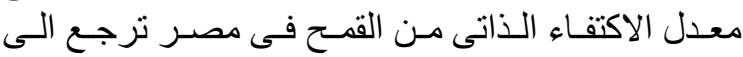

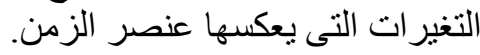

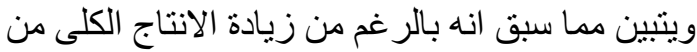

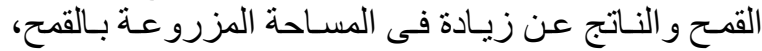

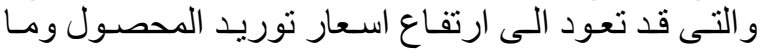

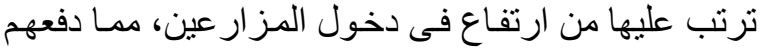

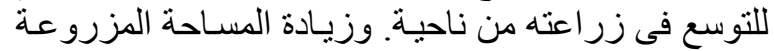

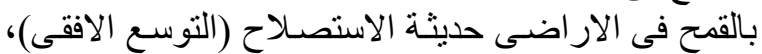

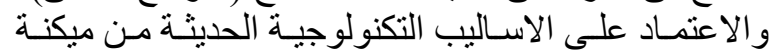

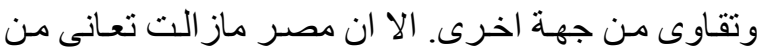

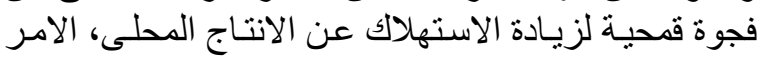

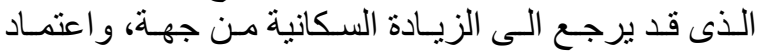

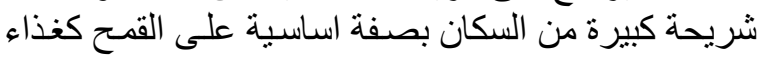

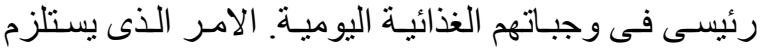

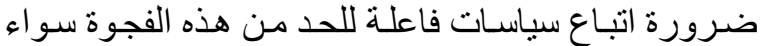
بزيادة الانتاج او ترشيد الاستهلاك.

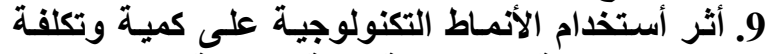

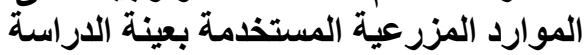
يتناول هذا الجزء در اســة التغير ات الحادثة في كمية المية 
جدول (5): تكلفة الموارد الزراعية والايرادات لفدان القدح وفقا للانماط التكنولوجية للميكنة الزراعية المستخدمة بمزارع عينة الدراسة بمنطقة غرب المنيا

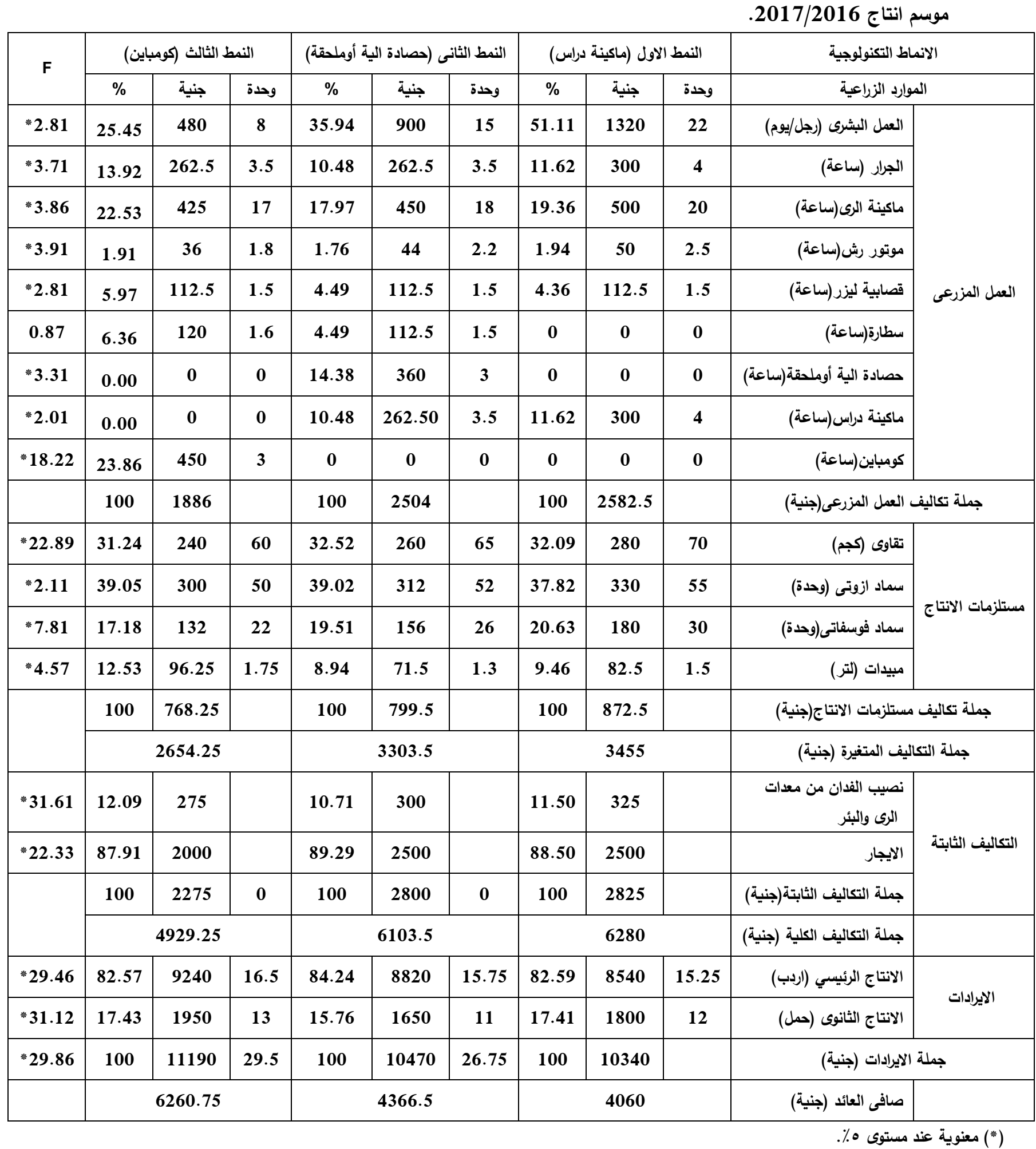


موتور الرش بين الأنماط التكنولوجية المستخدمة فى زر اعة محصول القمح بالعينة.

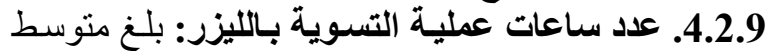

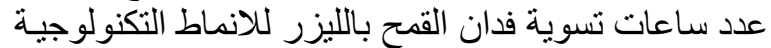

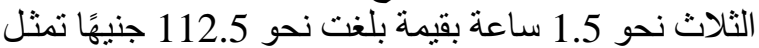

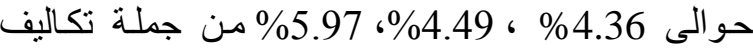
العمل المزر عى للانماط الثلاث على على الترتيب. 5.2.9 عدد ساعات الزراعة بالسطارة: تبين عدم أستخدام

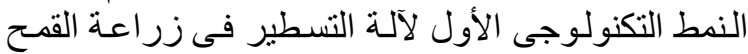

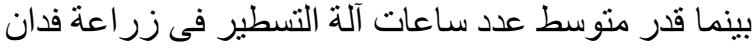

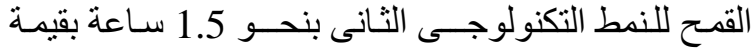

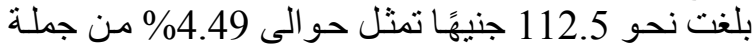
تكاليف العمل المزرعى، فى حين بلغ متوسط عدد ساعات

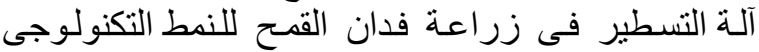

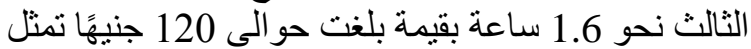
نحو 6.36\% من جملة تكاليف العمل المزرعى، حيثة حيث تبين

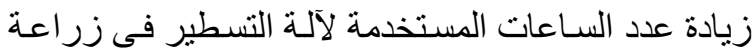

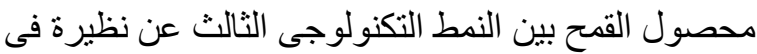

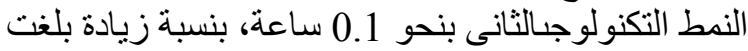

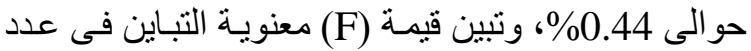

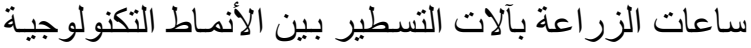
المستخدمة في زر اعة محصول آلات التصول القمح بالعينة. 6.2.9. عدد سـاعات تثـغيل المحشـات الأتيـة أوالملحقة

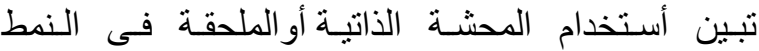

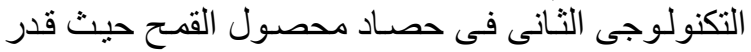

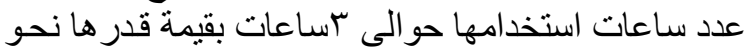

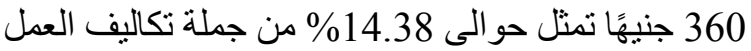

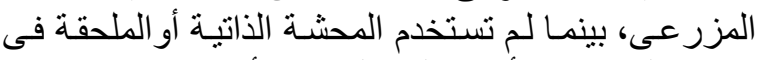
حصاد القمح فى الأنماط التكنولوجية الأخرى التون.

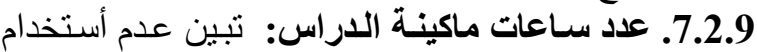

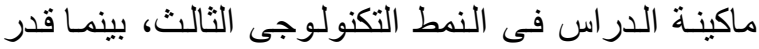

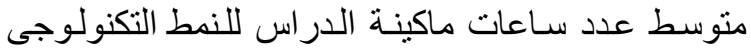

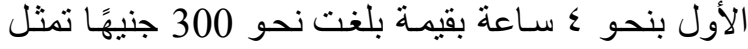

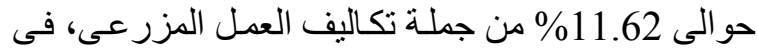

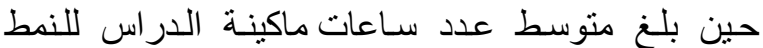

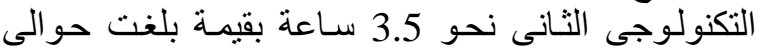
262.5 جنيهًا تمثل نحو 10.48\% من جملة تكاليف العمل فيل المزرعى، حيث تبين تناقص فى عدد السـاعات المستخدمة

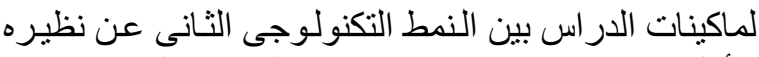
الأول بنحو 0.5 ساعة، بنسبة نقص بلغت حو الى الى 12.5 \%

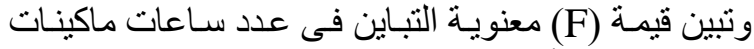

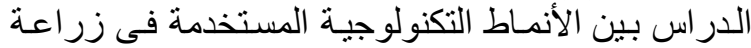

$$
\text { محصول القمح بالعينة. }
$$

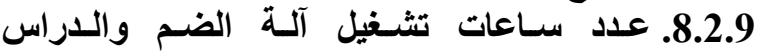
(الكومباين): قدرت عدد سـاعات أستخدام الكومباين في الفي الفي

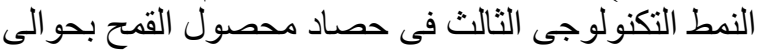

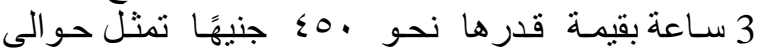

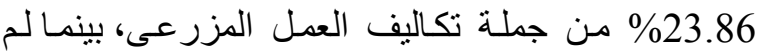

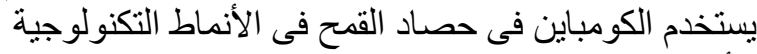

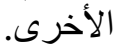

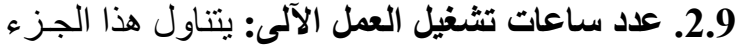

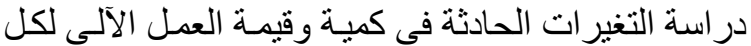

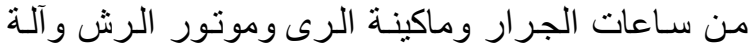

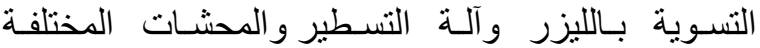
وماكينات الدر اس و آلّة الضم و اللدر اس و الكومباين، لكل الكل

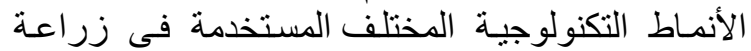
محصول القمح بالعينة.

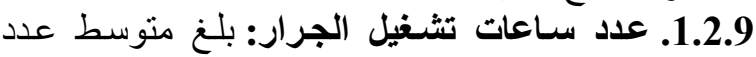

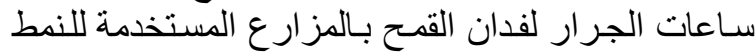

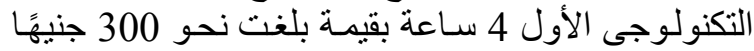

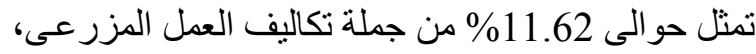

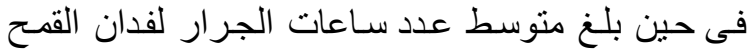

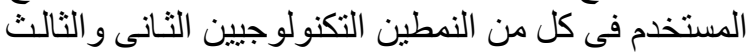

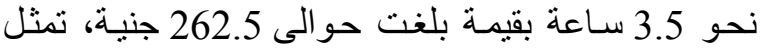
حوالى 10.48\%، 13.92\% من جملة تكاليف العمل

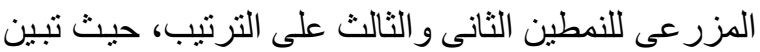

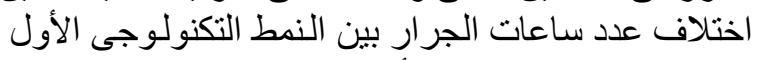
عن نظيره فى النمطين الأخرين بنحو بـ 0.5، 0.5 سـاعة النها

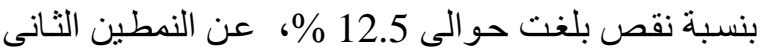

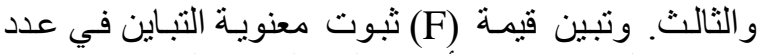

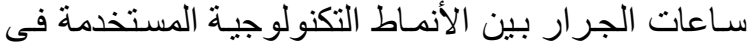
زر اعة محصول القمح بالعينة.

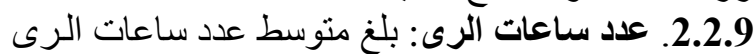

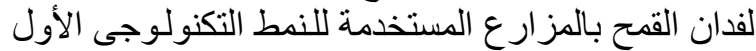

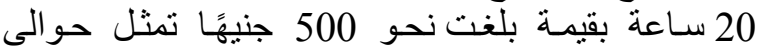

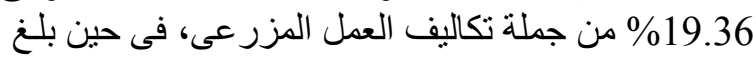
متوسط عدد ساعات الرى للفدان فى النمطين التكنولوجين التين لئن

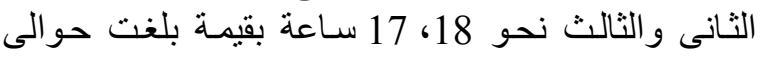

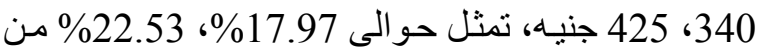

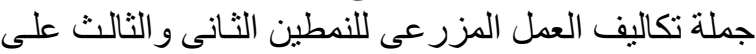

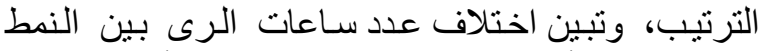

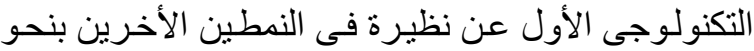

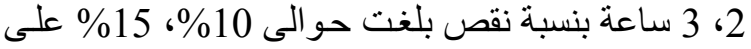

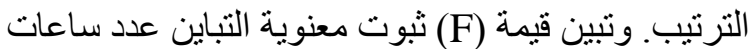

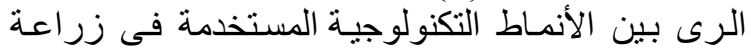
محصول القمح بالعينة.

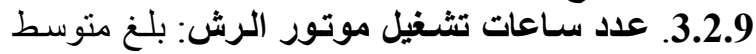

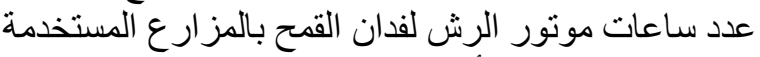

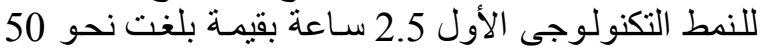

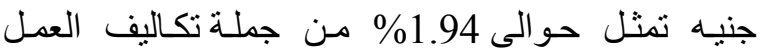

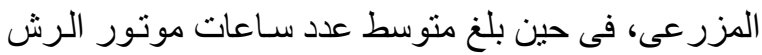

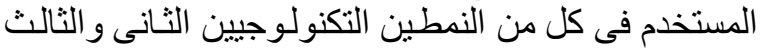

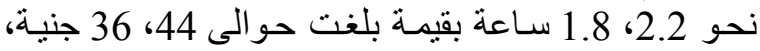
تمثل حو الى 1.76\%، 1.91\% من جملة تكاليف العمل

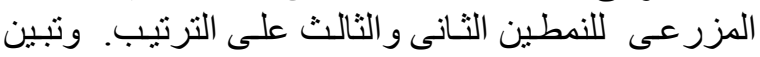

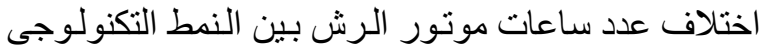
الأول عن نظيره فى النمطين الأخرين بنحو

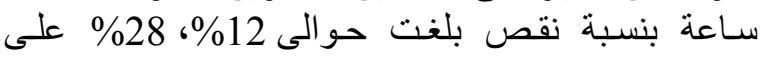
الترتيب. وتبين قيمة (F) ثبوت معنوية التباين عدد ساعات 
0.63\% من جملة تكاليف مستلزمات الإنتاج، في حين المين بلـغ متوسط الكميـة المستخدمة في النمطين التكنولوجينين

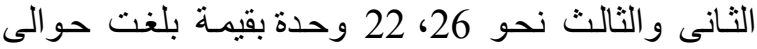

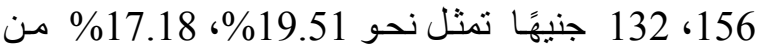
جملة تكاليف مستلزمات الإنتاج على الترتيب. حيثا فيث تبين

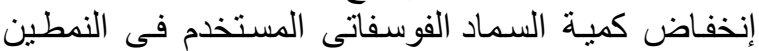

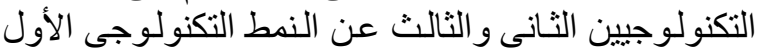

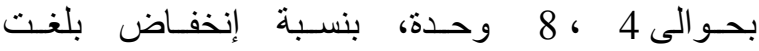

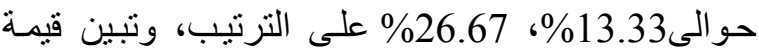
(F)

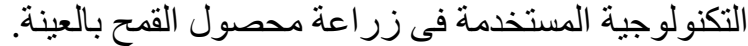

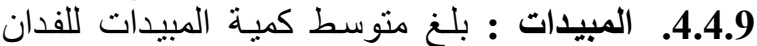
المستخدمة للنمط التكنولوجى الأول حو الى 1.5 لتر لتر بقيمـة

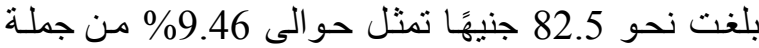
تكاليف مستلزمات الإنتاج، في حين بلغن متوسط كمبـة

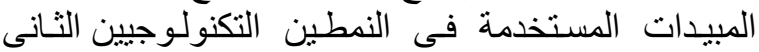

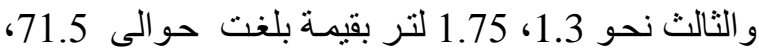
96.25 جنيةًا تمثل نحو 8.94\% مـن جملـة تكـاليف

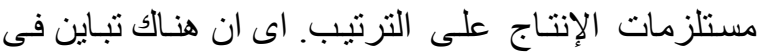

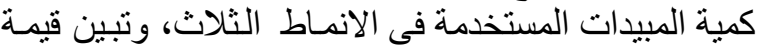

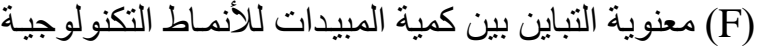

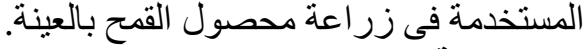
5.9. جملة تكاليف مستلزمات الإنتاج :بلغ منتوسط تكاليف الإنة

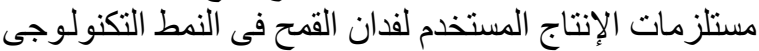

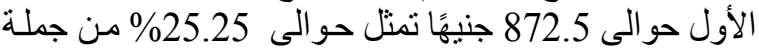

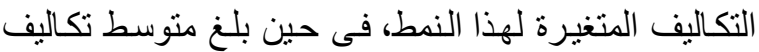

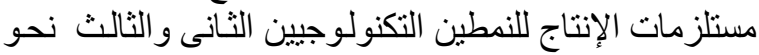
799.5، 768.25 جنيةًا تمثنل نحو 24.20 \% \% 28.94 \%

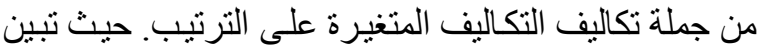
إنخفاض منوسط تكاليف مستلزمات الإنتاج فى النمطين

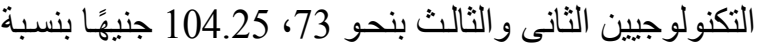
نقص بلغت حوالى 8.37 \%؛ 11.95 \% على الترتيب،

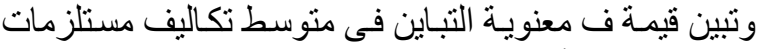

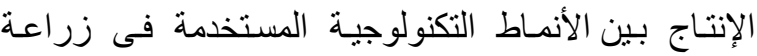
محصول القمح بالعينة. 10. جملة التكاليف المتغيرة للفدان: بلغ متوسط التكاليف

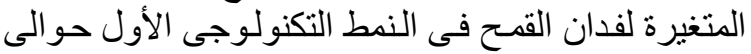

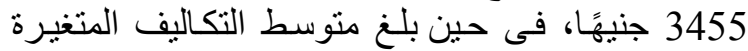

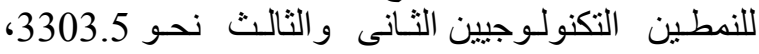

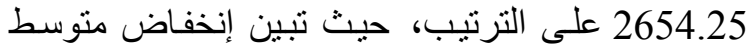
التكاليف المتغيرة فى النمطين التكنولوجيين الثانى والثالث عن النمط التكنولوجى الأول بنحو 649.25 جنيهًا بنسبة إنخفاض بلغت حو الى 4.38 \% \%

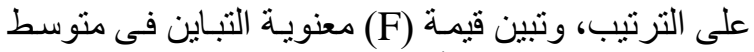

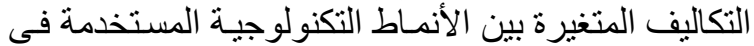
زراعة محصول القمح بالعينة.

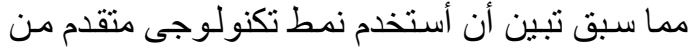

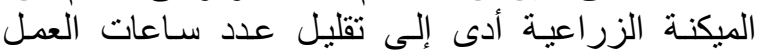

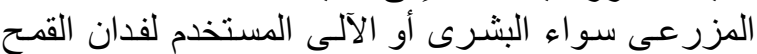

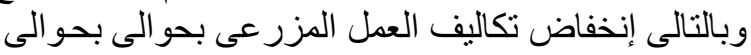

3.9. جملة تكساليف العمل المزرعى: بلـن متوسط تكاليف

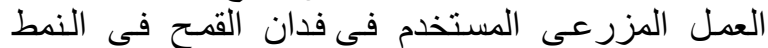

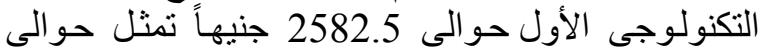

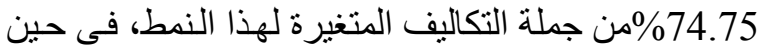
بلغ متوسط تكاليف العمل المزر جنى للنمطين التكنولوجيين الثانى والثالث نحو 2504، 1889 جنيهاً تمنثل نحو الثن

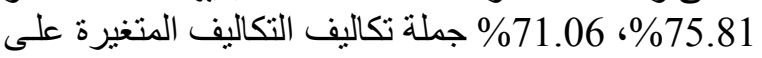

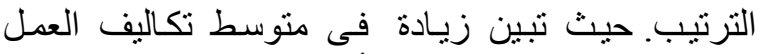
المزرعى للنمط التكنولوجى الأول عن نظيره في النمطين التكنولوجيين الثانى و الثالث بحو الى لـ 89.5،

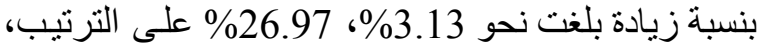

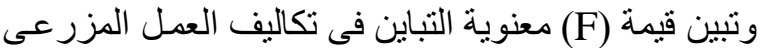

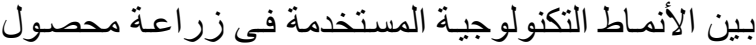
القمح بالعينة. 4.9. مستلزمات الإتتاج للفدان: يتتاول هذا الجزء مـن

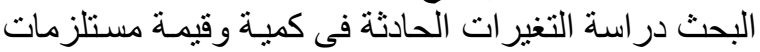

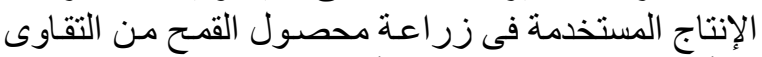

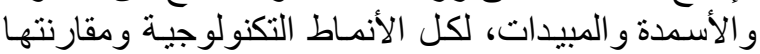

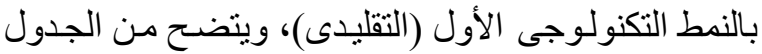
رقم (5) ما يلى: 1.4.9. التقاوى: قدر منوسط كميـة التقاوى لفدان القمح

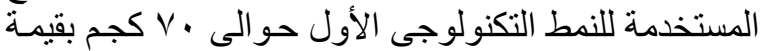
بلغت نحو 280 جنيهًا تمثنل حوالى 32.09\%من جملة تكـاليف مستلزمات الإنتاج، في حين بلـن متوسط كميـة

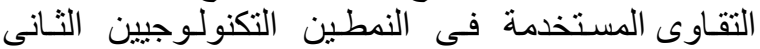

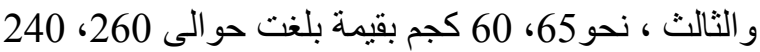

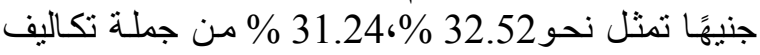

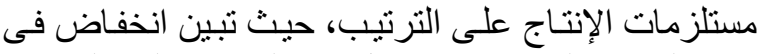

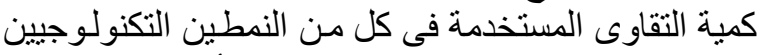

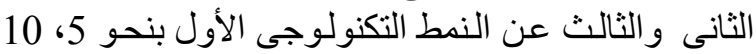

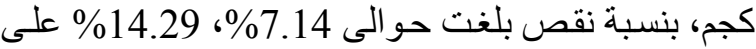

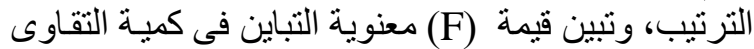

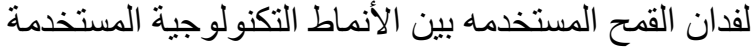
فى زر اعة محصول القمح بالعينة.

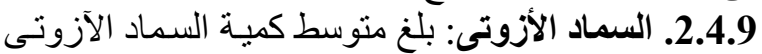

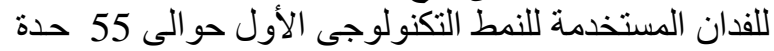
بقيمة بلغت نحو 330 جنيهًا تمثل حو الى الى

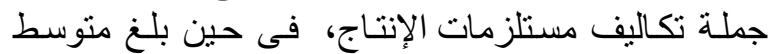
الكمية المستخدمة فى النمطين التكنولوجيين الثانى و الثالث

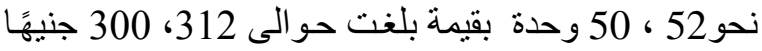

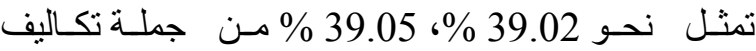
مستلزمات الإنتاج على الترتيب. حيث تبين إنخفاض كميـة السماد الأزوتى المستخدمة فى النمطين التكنولو لونيين الثين الثانى و الثالث بحو الى 3، 5 وحدة بنسبة نقص بلغت

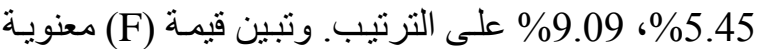

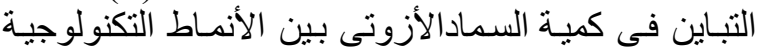
المستخدمة فى زر اعة محصول القمد بـ بالعينة.

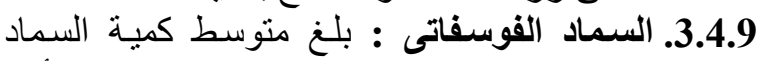

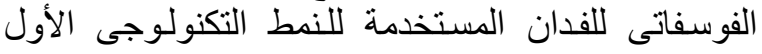

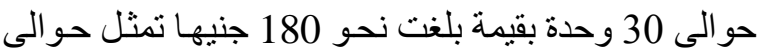


2.11. متوسط إنتاج الفدان من القمح : يتضح من بيانات

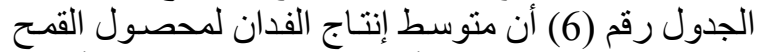

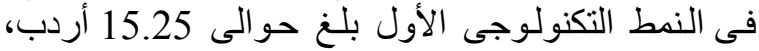

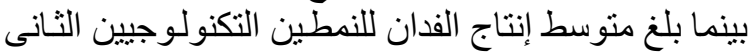

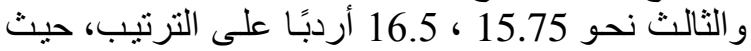

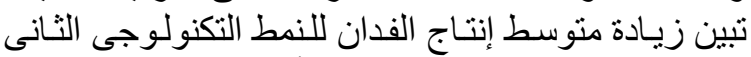
و الثالث عن النمط التكنولوجى الأول بنحو 0.5 ، 1.25

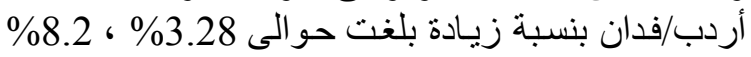

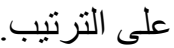

3.11. اجمالى ايرادات القدان: بلخ منوسط اير ادات فدان

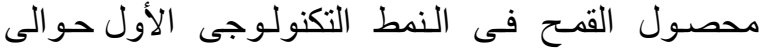
10340 جنيه، بينما بلغ متوسط الاير ادات للفذان للنئ اللمطين

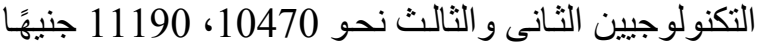
على الترتيب، حيث تبين زيادة متوسط الاير ادات للفدان فى ني

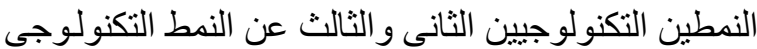
الأول بنحو 400 ، 850 جنيهًا بنسبة زيسادة بلغت النت حو الى لى 3.87 \% 8.22 \% \% على الترنيب.

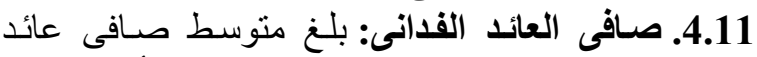

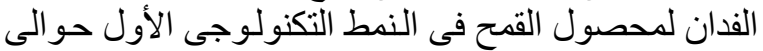

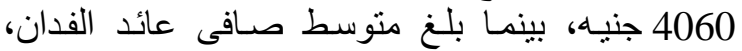

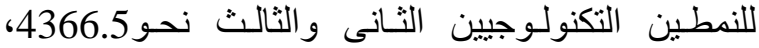

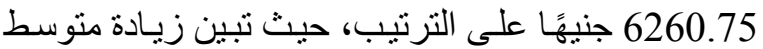

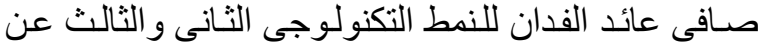
النمط التكنولوجى الأول بنحو 306.5، بنسبة زيسادة بلغت حوالى 7.55\% 54.21، 54.5 على

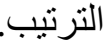
5.11. نسبة الإيرادات الكلية إلى التكاليف الكلية للفدان:

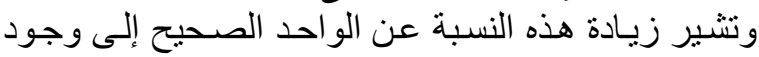
صافى عائد موجب، وقد بلغت نسبة الإير ادات الكلية إلى الى
89.5، 555.5 جنيهًا فى النمط التكنولوجى الثانى و الثالث الثكاث

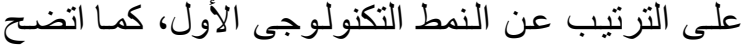

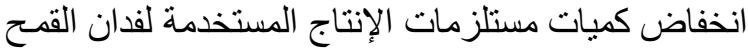

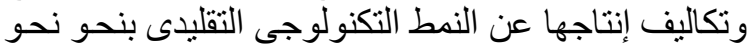

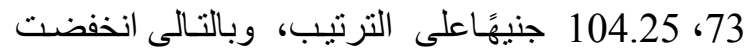

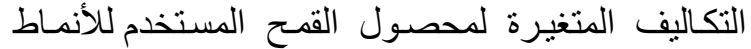

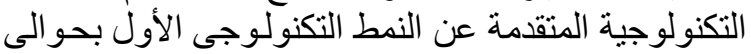

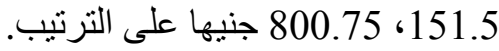

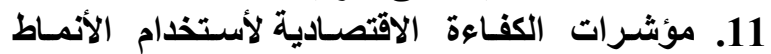

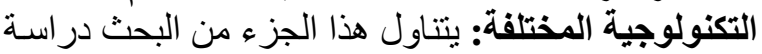
أهم مؤشر ات الكفاءة الاقتصادية المتمثلة فى معايير الدخل الدخل

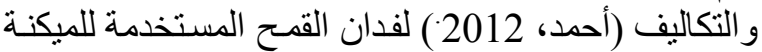

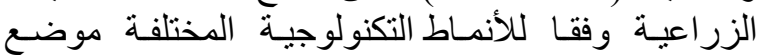
الدر اسة بعينة البحث. ويتضح من بيانات الجدول رقم (6) الزئة ما يلى: 1.11. التكاليف الكليهة: تتكون التكاليف الكلية من التكنة

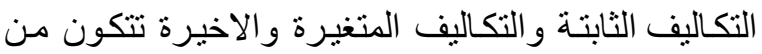

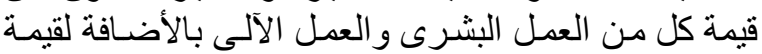

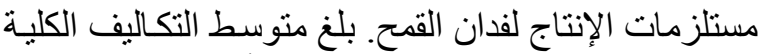
لفدان القمح فى النمط التكنولوجى الأول حوالى 6280

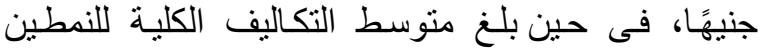
التكنولوجيين الثانى و الثالث نحو على الترتيب. حيث تبين إنخفاض منوسط التكاليف الكلية في النمطين التكنولوجيين الثنانى والثالث عن الثن النمط

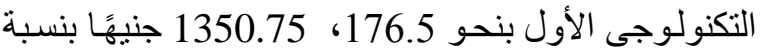

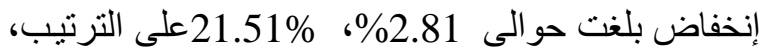

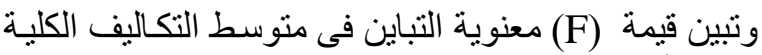
بين الأنماط التكنولوجية المستخدمة في زئنة زاعة محصول القمح بالعينة.

جدول (6): مؤشرات الكفاءة الاقتصادية لفدان القمح وفقا للانماط التكنولوجية للميكنة الزراعية بعينة الدراسة بمنطقة غرب

المنيا موسم 2016 إنتاج /2017.

\begin{tabular}{|c|c|c|c|}
\hline النمط الثالث (كومباين) & (حصادة الية أوملىحقة) & 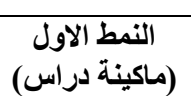 & الانماط التكنولوجية \\
\hline & & & مؤشرات الكفاءة الاقتصادية للفدان \\
\hline 16.5 & 15.75 & 15.25 & متوسط انتاج الفدان (اردب) \\
\hline 2654.25 & 3303.5 & $\mathbf{3 4 5 5}$ & جملة التكاليف المتغيرة (جنية) \\
\hline 2275 & 2800 & 2825 & جملة التكاليف الثابتة (جنية) \\
\hline 4929.25 & 6103.5 & 6280 & جملة التكاليف الكلية (جنية) \\
\hline 9240 & 8820 & 8540 & قيمة الناتج الرئيسي (جنية) \\
\hline 1950 & 1650 & 1800 & قيمة الناتج الثانوى (جنية) \\
\hline 11190 & 10470 & 10340 & جملة الايرادات (جنية) \\
\hline 6260.75 & 4366.5 & 4060 & صافى العائد الفدانى (جنية) \\
\hline 227.01 & $\mathbf{1 7 1 . 5 4}$ & 164.65 & نسبة الايرادات الكلية الى التكاليف الكلية \% \\
\hline 421.59 & 316.94 & 299.28 & نسبة الايرادات الكلية الى المتغيرة الكلية \% \\
\hline 127.01 & 71.54 & 64.65 & نسبة صافى العائد للتكاليف الكلية \% \\
\hline 235.88 & 132.18 & 117.51 & نسبة صافي العائد للتكاليف المتغيرة \% \\
\hline 8.80 & 10.90 & 11.21 & كمية التعادل لتفطية التكاليف الكلية (اردب) \\
\hline 4.74 & 5.90 & 6.17 & كمية التعادل لتغطية التكاليف المتغيرة(اردب) \\
\hline 298.74 & 387.52 & 411.80 & سعر التعادل لتظطية التكاليف الكلية (ج/اردب) \\
\hline 160.86 & 209.75 & 226.56 & سعر التعادل لتغطية التكاليف المتغيرة (ج/ردب) \\
\hline
\end{tabular}


2.12. كمية التعادل لتفطية التكاليف الكلية: يوضح هذا

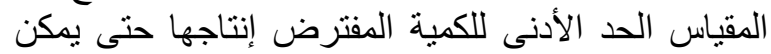

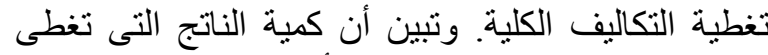

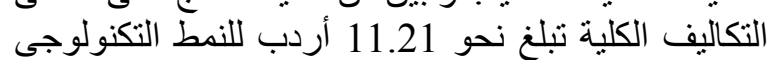
الأول، تمثل حوالى 74\% من متوسط إنتاج الفدان لهذا

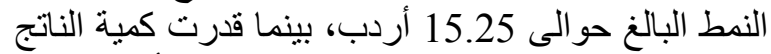

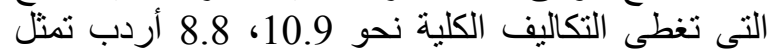
حوالى69 \%، 53\% من منوسط إنتاج الفدان وفقا للنمطين الثانى والثالث و البالغ حوالى أردب للفدان على الترتيب.

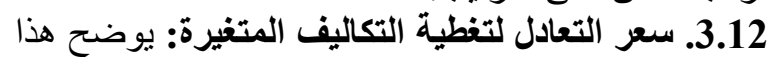

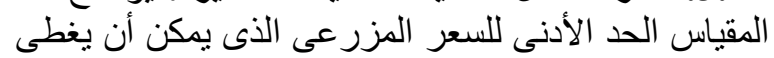

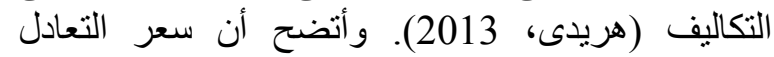

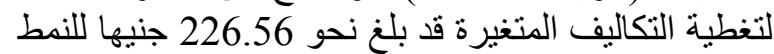

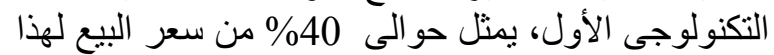

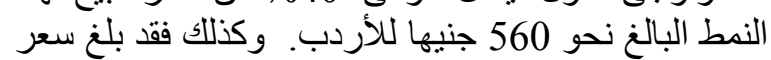
التعادل لتغطية التكاليف المتغيرة نحو 160.80 .86 209.75

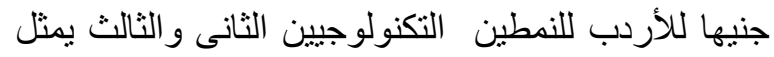

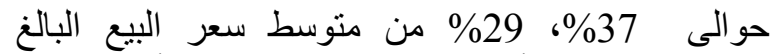

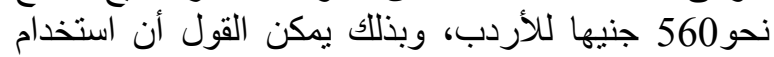

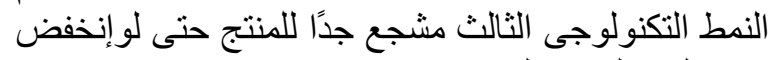
سعر البيع الى حو الى 71: 7.12\%. 4.12. كمية التعادل لتفية التكاليف المتغيرة: يوضح

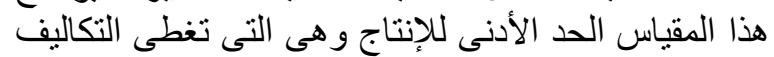

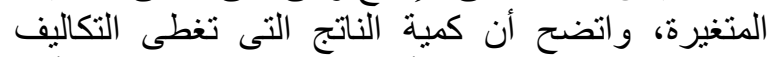

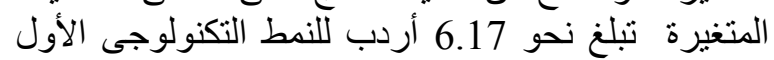

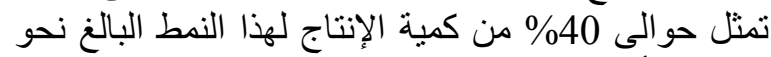

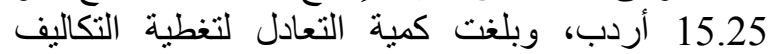

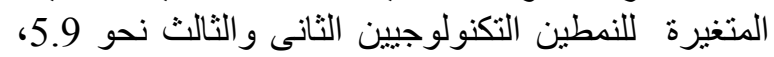

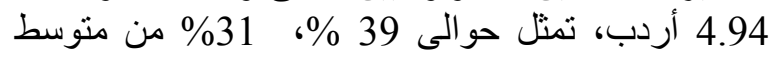

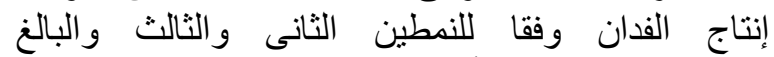

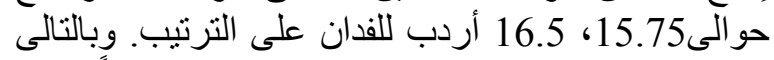

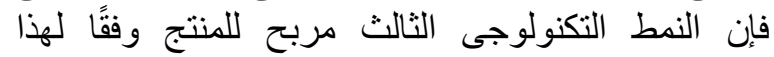

13. التحليل الاقتصادى والقياسىى لاوال إنتاج القمح وفقًا

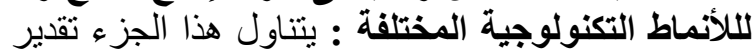

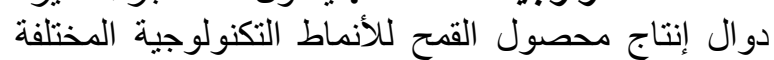

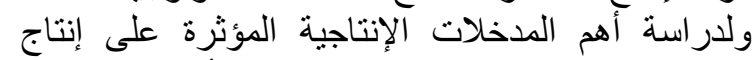

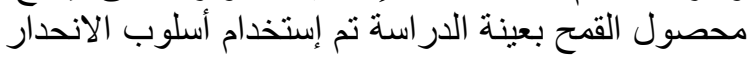

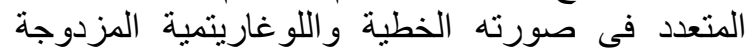

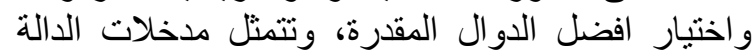

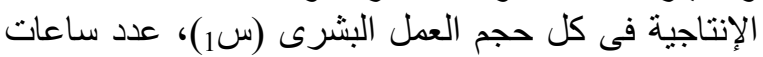

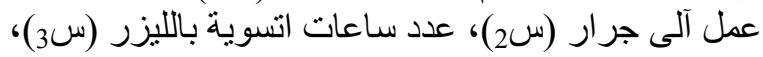

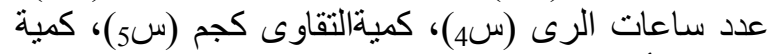

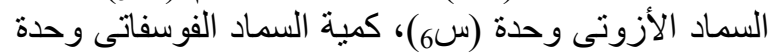

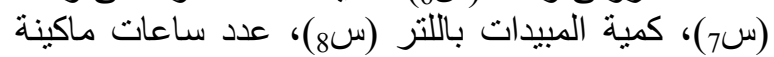

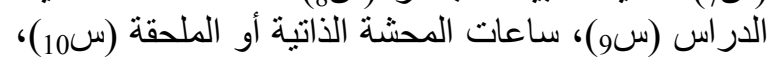

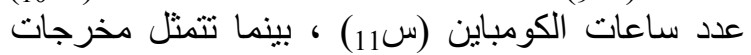

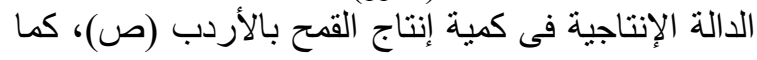

التكاليف الكلية للأنماط التكنولوجيـة المختلفة، المستخدمة

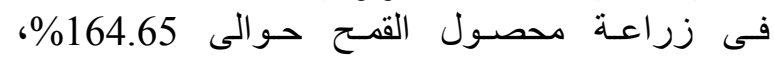

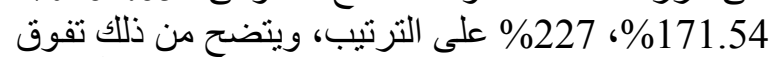

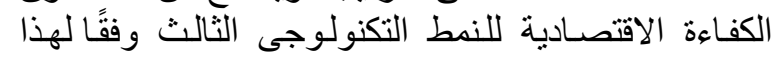

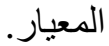

6.11. نسبة الإيرادات الكلية إلى التكاليف المتغيرة

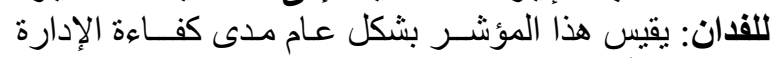

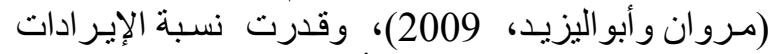

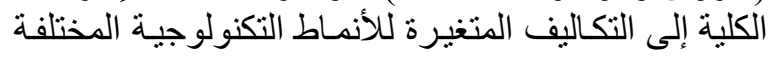

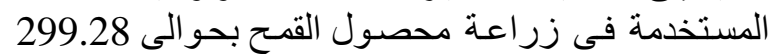

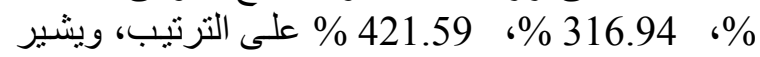
ذلك إلى تفوق الكفاءة الاقتصادية للنمط التكنولوجى الثالث وفقًا لهذا المعيار.

7.11. نسبة صـافى العائد الى التكاليف الكلية للفدان:

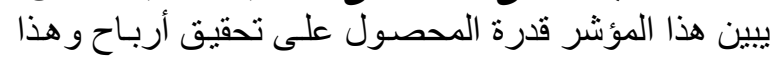

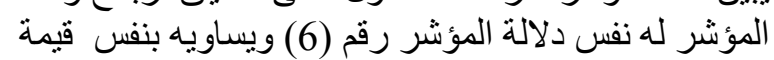

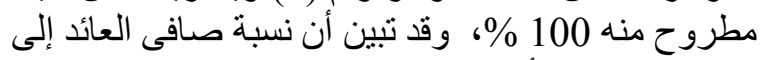

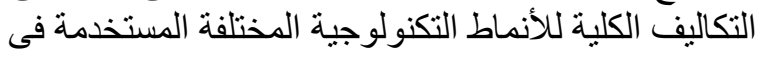

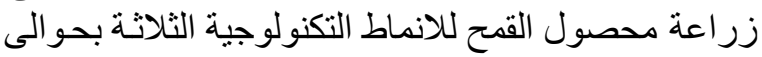

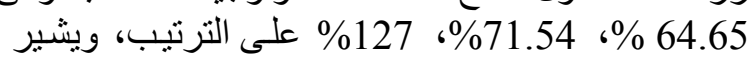
ذللك إلى تفوق الكفاءة الاقتصادية للنمط التكنولوجى الثنالث و فقًا لهذا المعيار .

8.11. نسبة صافى العائد للتكاليف المتفيرة الفدانية: تبين

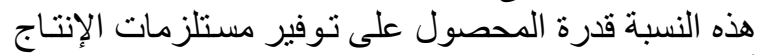

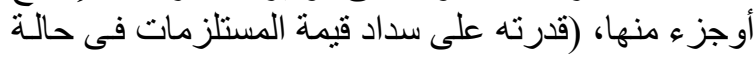

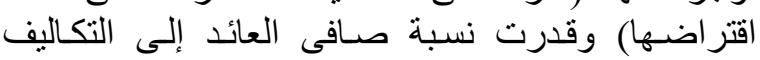

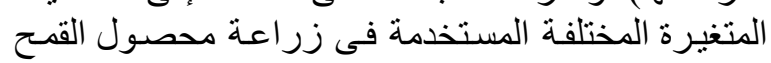

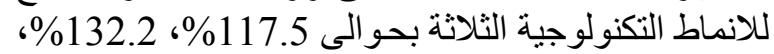
235.9\% على الترتيب، ويشير ذلك إلكى تلى الكوق الكفاءة

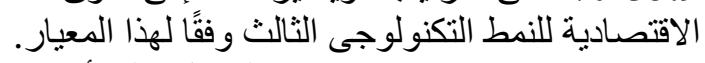

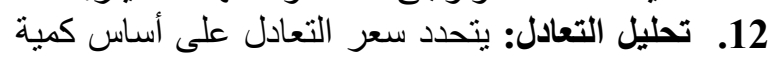

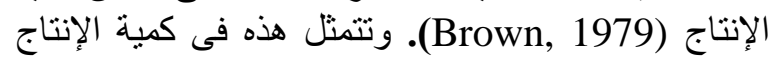
الفعلية بالاردب للفدان للانماط التكنولوجية المختلفة فئة بعينة

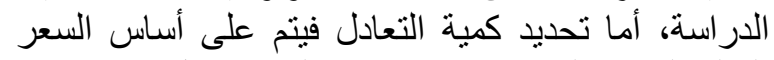

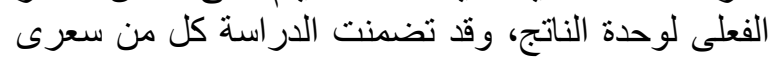
وكميتى التعادل لتغطية كل من التكاليف الكلية والمتغيرة

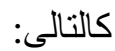

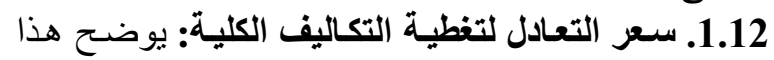

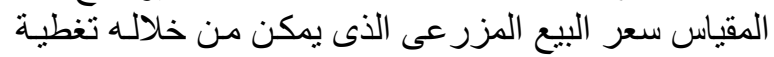

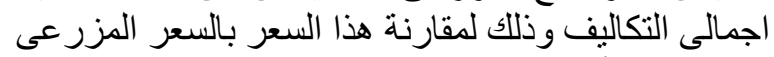

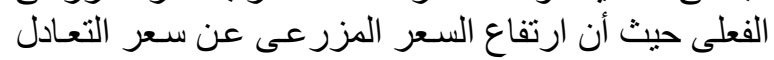

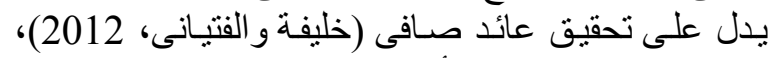
وتوضح بيانات الجدول أن سعر التعادل لتغطية التغية التكاليف

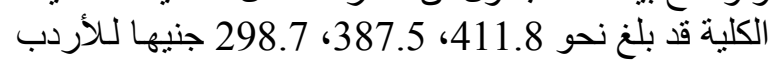

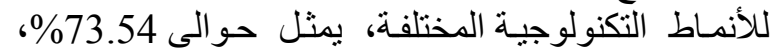

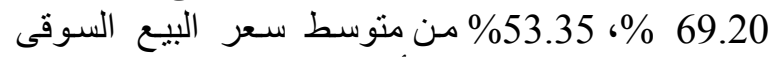

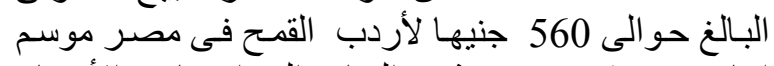
انتاج 2017/2016، وتشير النتائج إلى إنخفاض الأستعار

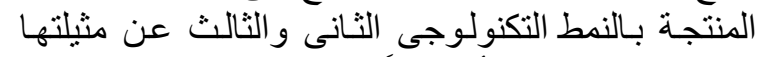
بالنمط التكنولوجى الأول طبقًا لهذا المعيار. 
10 \% تودى إلى زيادة فى كمية إنتاج محصول القمح

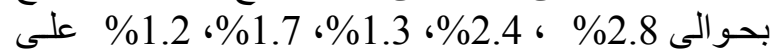

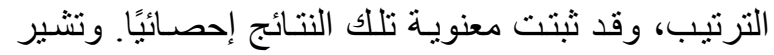

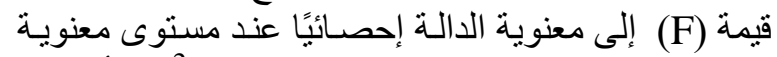

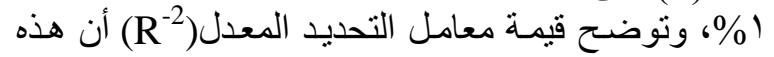

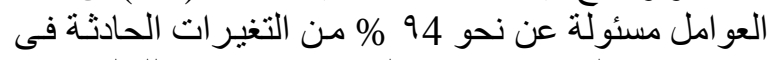

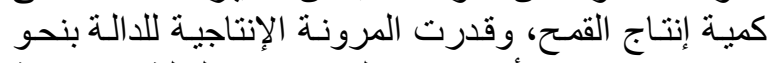

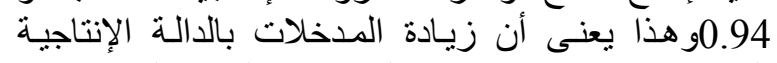

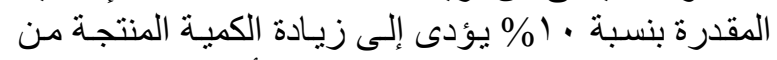

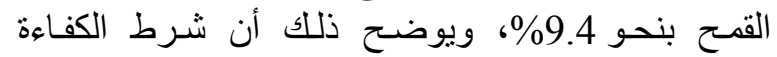

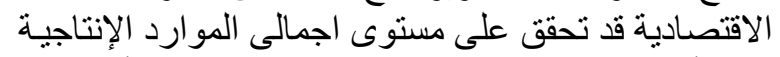

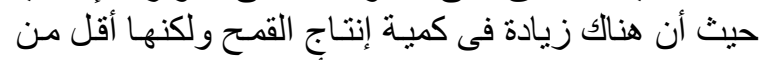

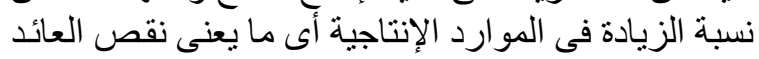
إلى السعة. وبالنسبة للنمط التكنولوجى الثالث (الكومباين) وكما

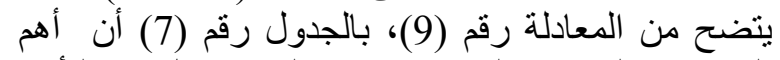

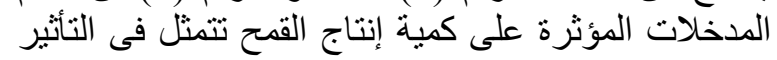

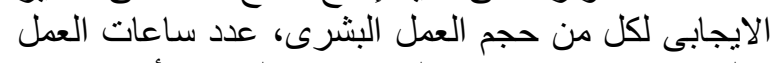

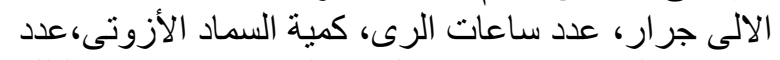

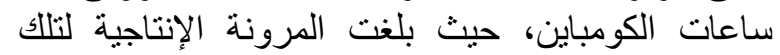

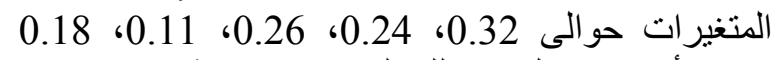

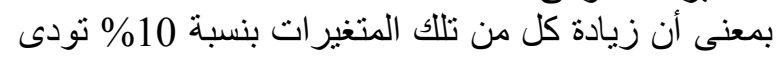

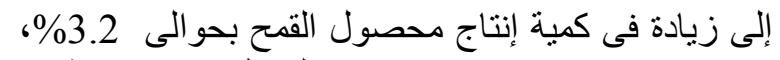

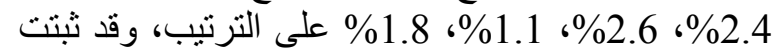

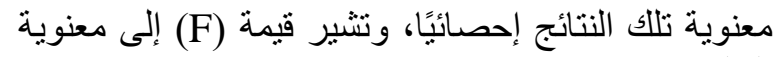

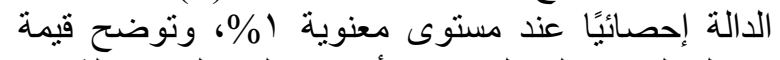

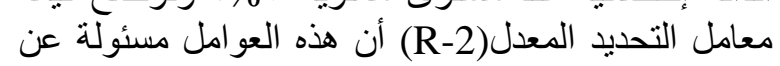

يتناول تقدير الكفاءة الاقتصادية لعناصر الإنتاج

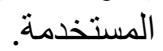
وتثير بيانات جدول رقم (7)، إلي دوال انتاج محصول

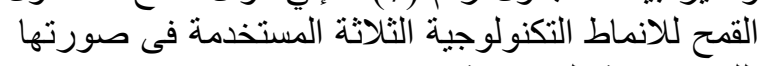
اللوغاريتمية المزدوجة (Heady and Dillon, 1961) لاراسة أهم المدخلات الإنتاجية المؤثرة على إلى إنتاج

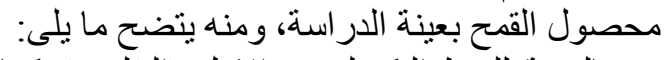

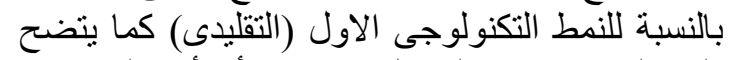

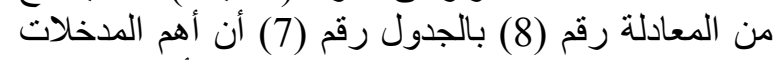

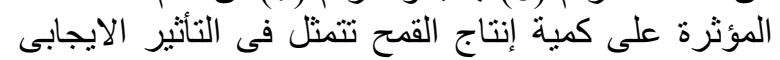

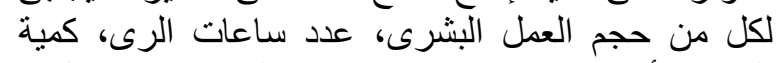

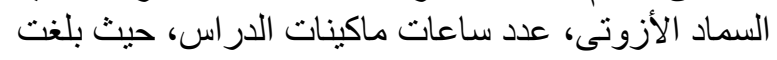
المرونة الإنتاجية لتلأك المتغيرات ماتكينات حوالى

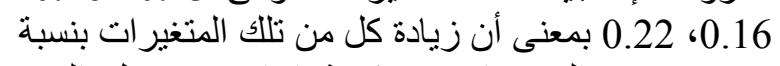

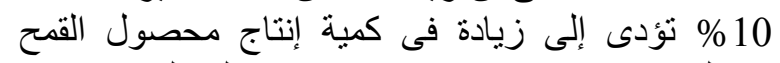

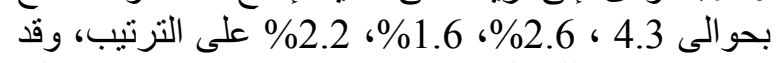

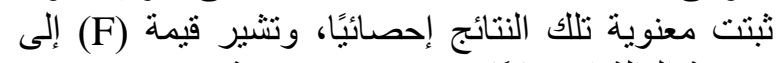

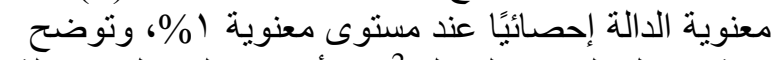

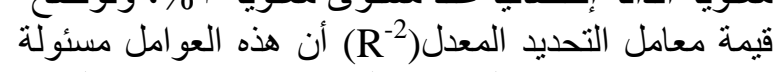
عن نحو 97 \% من التغير ات الحادثة في كمية إنتاج القمح،

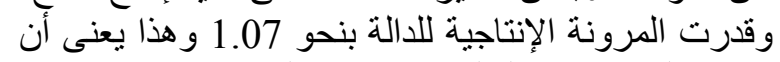

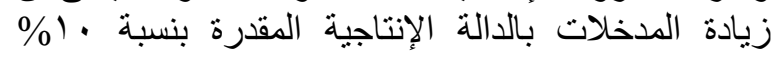

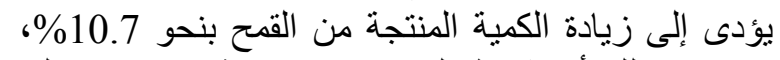

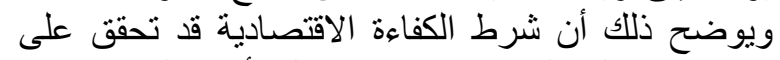

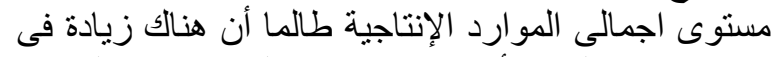

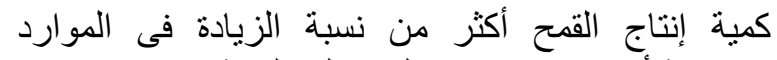
الإنتاجية أى ما يعنى زيادة العائد إلى السعة.

جدول (7): دوال انتاج القمح للانماط التكنولوجية المستخدمة فى منطقة الدراسة موسم انتاج 2017/2016.

\begin{tabular}{|c|c|c|c|c|}
\hline $\mathbf{F}$ & $\mathbf{R}^{-2}$ & المعادلة & رقم & النمط \\
\hline${ }^{* *} 122.88$ & 0.956 & 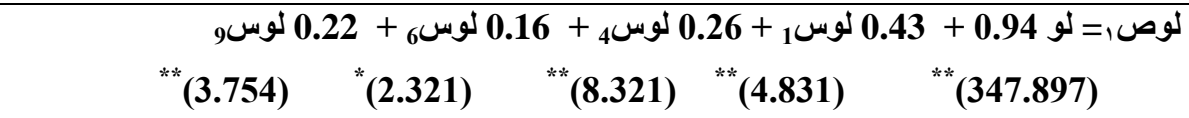 & 7 & الاول \\
\hline ***117.78 & 0.938 & 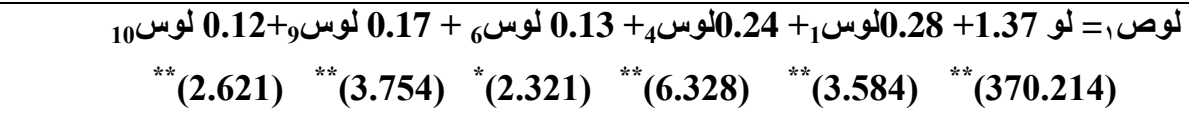 & 8 & الثانى \\
\hline **123.18 & 0.964 & 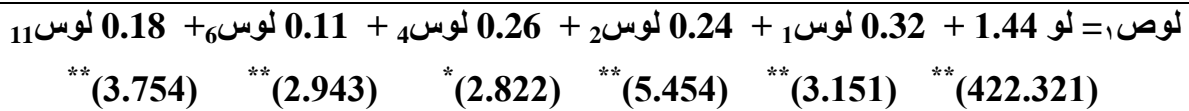 & 9 & الثالث \\
\hline
\end{tabular}

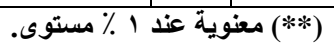

نحو 9 \% من التغيرات الحادثة فى كمية إنتاج القمح،

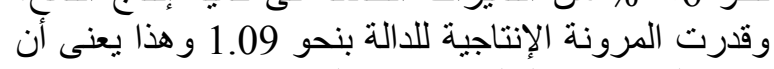

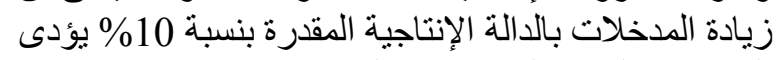

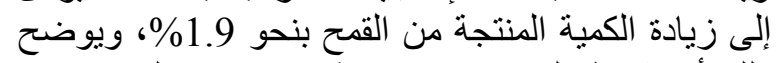

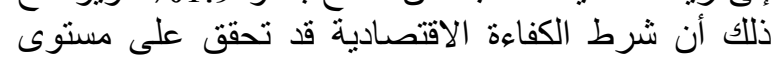

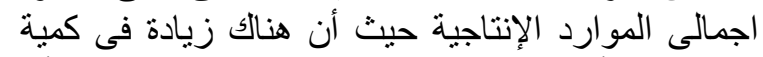

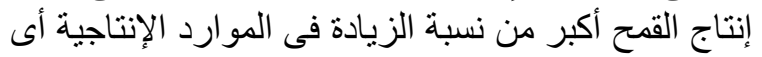
ما يعنى زيادة العائد إلى السعة. ن السئ.
المصدر: نتائج التحليل الاحصائى للبيانات الميدانية باستخدام برنامج معوبه

أمسا بالنسبة للنمط التكنولـوجى الثـانى (محثـات ذاتيـة

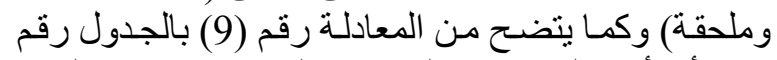

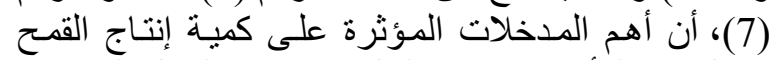

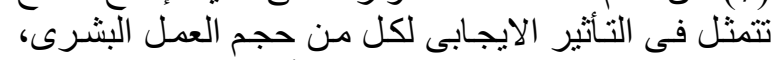

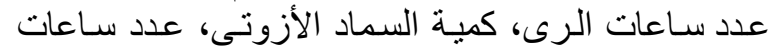

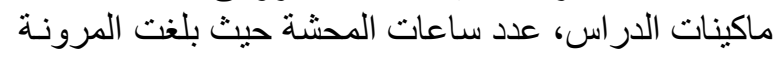

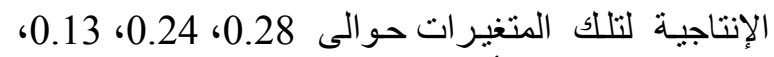
0.17، 0.12 بمعنى أن زيادة كل من تلأك المتغيرات بنسبة 


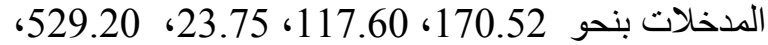
382.20 جنيـ على الترتيـــب، بينما بلغ أجـر يـوم العمل

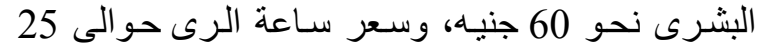

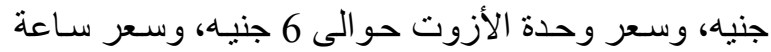

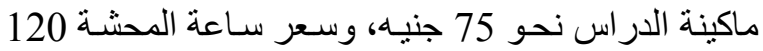
جنية ويعنى ذلك أن شرط الكفاءة الاقتصادية قد تحقق على الى الى

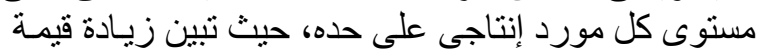

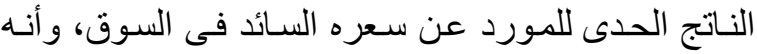

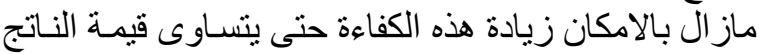
الحدى للمورد مع سعره السائد في السوة السوق.

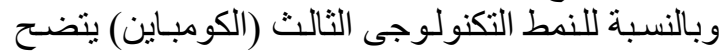

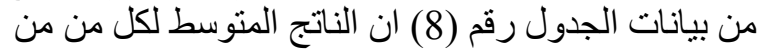

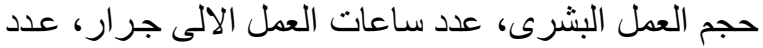

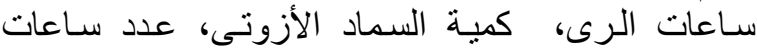

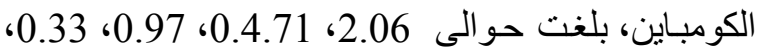

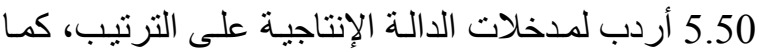

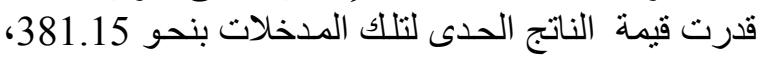

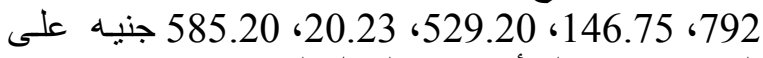
الترنيب، بينما بلغ أجر يوم العمل البشرى نحو 60 جنيه جنيه،

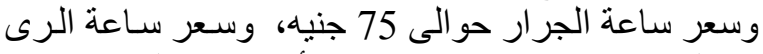

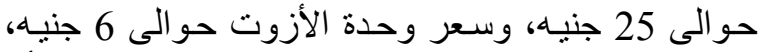

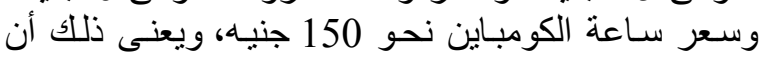
شرط الكفاءة الاقتصادية قد تحقق على مسنوى كلى كل مورد

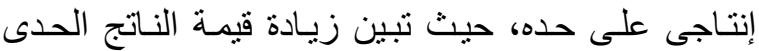

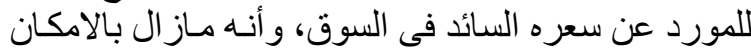

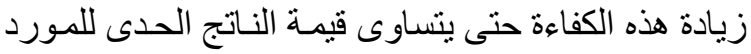

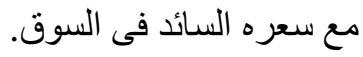

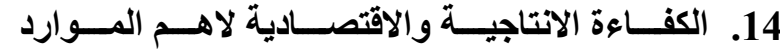

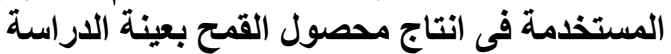

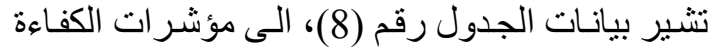
الإنتاجية والاقتصادية المقدر (الدقله، 2014) لاهية الهم الموارد

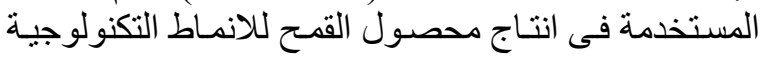
المستخدمة بعينة الدر استة ومنه يتبين ما يليى:

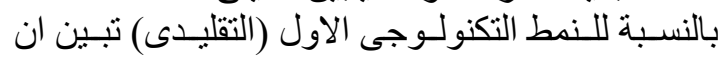

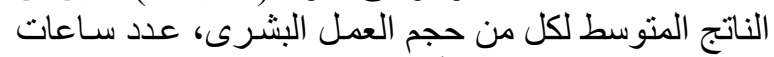

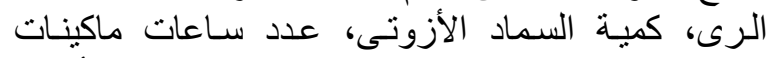

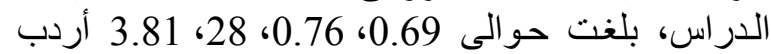

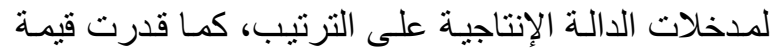

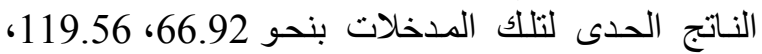

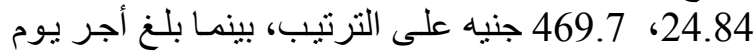

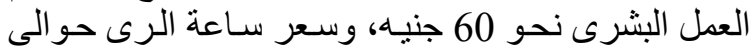

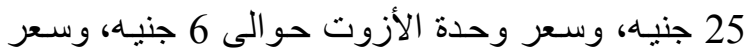

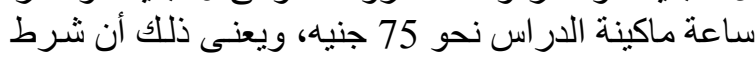

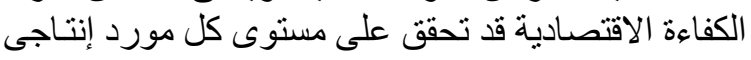

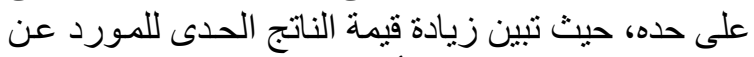

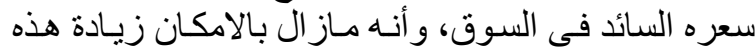

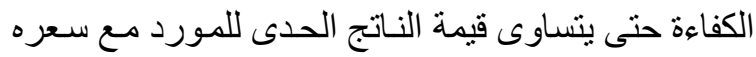

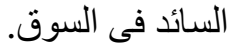

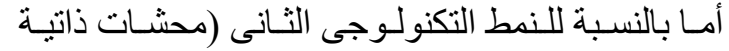

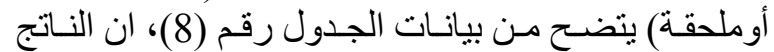

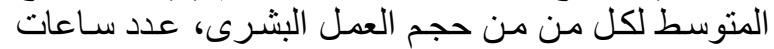

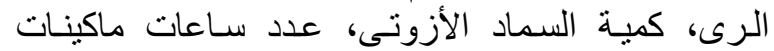

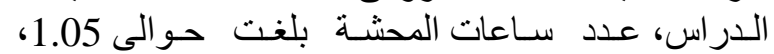

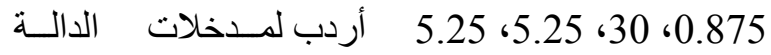
الإنتاجية على الترتيب، كما قدرت قيمة الناتج الحدى لتلك لك

جدول رقم (8): مؤشرات الكفاءة الإتتاجية والاقتصادية المقدرة لاهم الموارد المستخدمة فى انتاج محصول القمح للانمـاط التكنولوجية المستخذمة بعينة الاراسة.

\begin{tabular}{|c|c|c|c|c|c|c|}
\hline \multirow{2}{*}{ الاقتصادية } & \multirow{2}{*}{ سعرد } & \multirow{2}{*}{ الناتج الحدى } & \multicolumn{2}{|c|}{ الناتج } & \multirow{2}{*}{ المورد الانتاجي } & \multirow{2}{*}{ البيان النمط } \\
\hline & & & 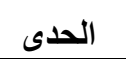 & المتوسط & & \\
\hline 2.78 & 60 & 166.92 & $\mathbf{0 . 3 0}$ & 0.69 & حجم العمل البشرى (س1) & \multirow{4}{*}{ 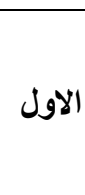 } \\
\hline 4.7824 & 25 & 119.56 & 0.21 & 0.76 & عدد ساعات الرى (س4) & \\
\hline 4.14 & 6 & 24.84 & 0.04 & 0.28 & كمية السماد الأزوتى (س6) & \\
\hline 6.26 & 75 & 469.70 & 0.84 & 3.81 & عدد ساعات ماكينة الدراس (سوو) & \\
\hline 2.84 & 60 & 170.52 & 0.3045 & 1.05 & حجم العمل البشرى (س1) & \multirow{5}{*}{ الثانى } \\
\hline 4.70 & 25 & 117.6 & 0.21 & 0.875 & عدد ساعات الرى (س4) & \\
\hline 3.96 & 6 & 23.75 & 0.04 & 0.30 & كمية السماد الأزوتى (س6) & \\
\hline 7.06 & 75 & 529.20 & 0.95 & 5.25 & ساعات ماكينة الدراس (سو) & \\
\hline 3.19 & 120 & 382.20 & 0.68 & 5.25 & ساعات المحشة الذاتية أو الملحقة (س10) & \\
\hline 6.35 & 60 & 381.15 & 0.68 & 2.06 & حجم العمل البشرى (س1) & \multirow{5}{*}{ 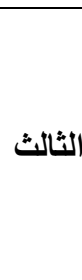 } \\
\hline 10.56 & 75 & 792.00 & 1.41 & 4.71 & عدد ساعات عمل آلى جرار (س2) & \\
\hline 5.87 & 25 & 146.75 & 0.26 & 0.97 & عدد ساعات الرى (س4) & \\
\hline 3.39 & 6 & 20.33 & 0.04 & $\mathbf{0 . 3 3}$ & كمية السماد الأزوتى (س6) & \\
\hline 3.90 & 150 & 585.20 & 1.05 & 5.50 & عدد ساعات الكومباين (س11) & \\
\hline
\end{tabular}


الزراعية، جمهورية مصر العربية، مجلد (59)، عدد

$$
\text { . }
$$

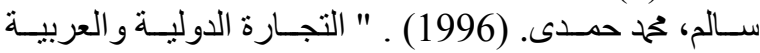

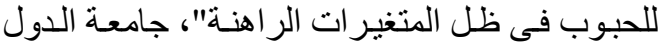

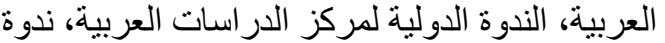

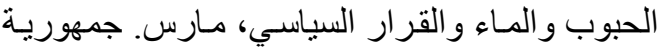
مصر العربية.

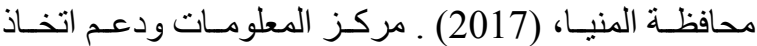

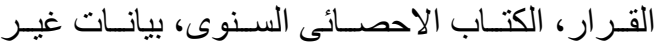

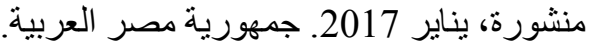

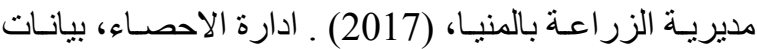
غير منشورة، يناير. جمهورية مصر العربية.

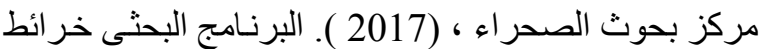

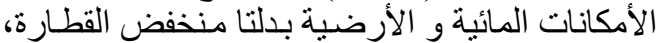

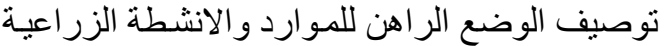

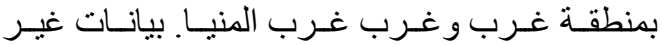
منشورة، مركز بحوث الصحر اء، بيناير.

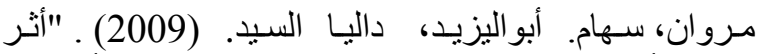

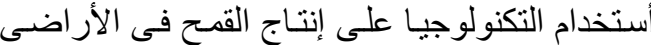

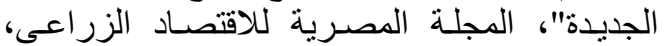
جمهورية مصر العربية.المجلد 19، العدد 2، مـارس. ص: 189. هريدى، عزت صنبره أحمد. (2013)" أثر أستخدام

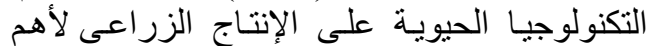

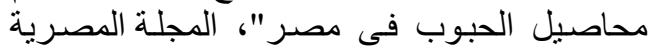
للاقتصاد الزر اعى، جمهورية مصر العربية، المجلد

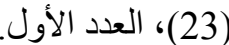

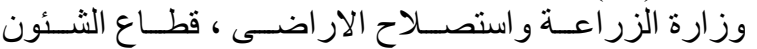
الاقتصادية ، نشرة الإقتصاد الزر اعلى اعى اعداد مختلفة.

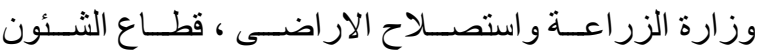
الاقتصادية ، نشرة التجارة الخار جية، اعداد مختلفة.

\section{REFERENCES}

Brown Maxwell L, "Farm Budgets: From Farm Income Analysis to Agricultural projects Analysis (1979). " Baltimore, Md, Johns Hopkins University Press.

Heady E.O. and Dillon John. L. (1961). "Agricultural production function" Iowa state university press, Ames Iowa, U.S.A., p, 2150.
في ضوضيات النتائج البحثبة المتحصل عليها يوصسى البحث

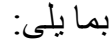

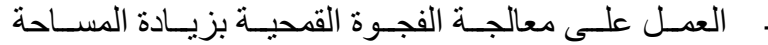

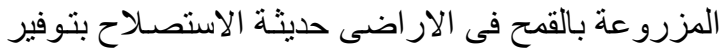

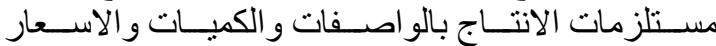

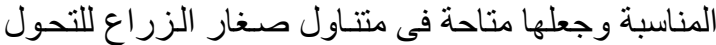

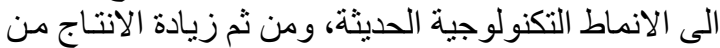

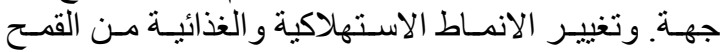
ومنتجاته من جهة ونئر اخرى.

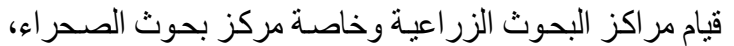

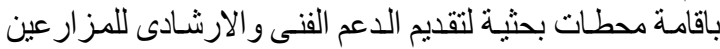

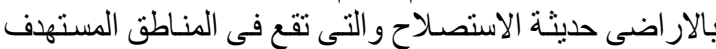
زراعتها ومن اهمها منطقة غرب الإنها المنيا.

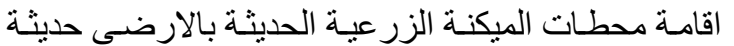
الاستصلاح و اتاحتها للمنتجين باسعار مناسبة الرية.

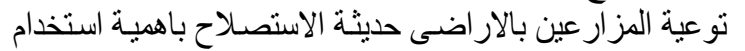

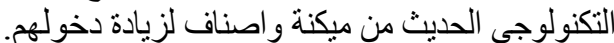

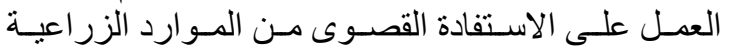

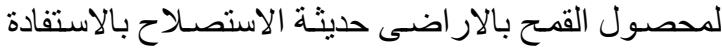

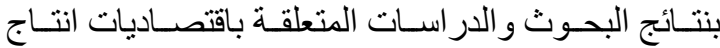

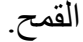

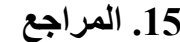

أحمد، حمح أحمد. "(2012). أثر أستخدام تكنولوجيا الأصناف

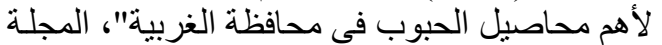

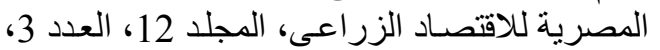

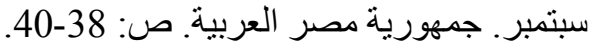

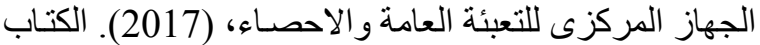

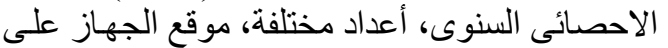
الانترنت. الاحتى

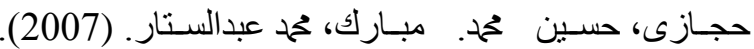

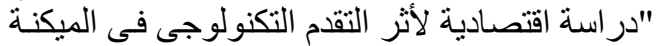

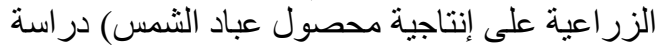

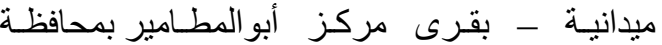

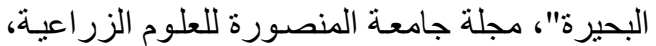

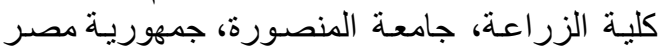

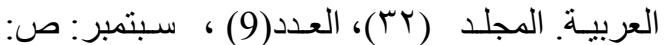

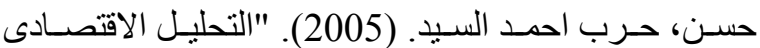

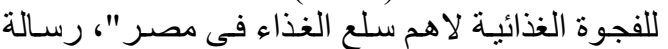

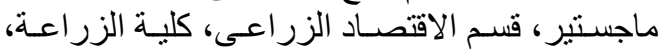
جامعة المنيا ـ جمهورية مصر الأية العربية.

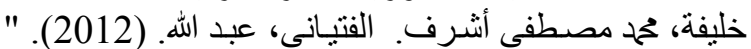

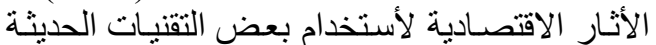

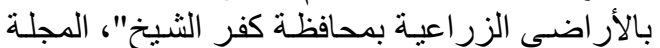

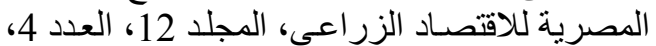
ديسمبر. جمهورية مصر العربية. الدقله، أمين عبدالرؤف. (2014). الدر اسـة إقتصـادية لأثر

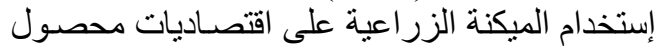

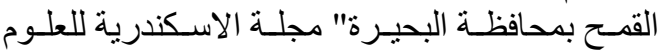

